\title{
Diastereoselective Mukaiyama Aldol Reaction of 2-(Trimethylsilyloxy)furan Catalyzed by Bismuth Triflate
}

\author{
Thierry Ollevier, ${ }^{\star}$ Jean-Emmanuel Bouchard, and Valerie Desyroy \\ Département de chimie, Université Laval, Québec (Québec), Canada G1K 7P4 \\ thierry.ollevier@chm.ulaval.ca
}

Supporting Information

\section{Contents:}

Experimental Section

$\mathrm{S}-2$ to $\mathrm{S}-8$

Copies of ${ }^{1} \mathrm{H}$ NMR and ${ }^{13} \mathrm{C}$ NMR spectra for compounds 3a-n, 3n'

S-9 to S-38 


\section{Experimental section}

General: Infrared spectra were recorded on a FT infrared spectrometer and are reported in reciprocal centimeters $\left(\mathrm{cm}^{-1}\right) .{ }^{1} \mathrm{H},{ }^{13} \mathrm{C}$, and ${ }^{19} \mathrm{~F}$ spectra were recorded on a $400 \mathrm{MHz}$ magnetic resonance spectrometer in $\mathrm{CDCl}_{3}$. For ${ }^{1} \mathrm{H} \mathrm{NMR}$, tetramethylsilane (TMS) served as internal standard $(\delta=0)$ and data are reported as follows: chemical shift, multiplicity $(\mathrm{s}=$ singlet, $\mathrm{d}=$ doublet, $\mathrm{dd}=$ doublet of doublet, $\mathrm{dt}=$ doublet of triplet, $\mathrm{t}=$ triplet, $\mathrm{m}=$ multiplet, and $\mathrm{br}=\mathrm{broad}$ ), coupling constant in $\mathrm{Hz}$, integration, and assigment. For ${ }^{13} \mathrm{C} \mathrm{NMR}, \mathrm{CDCl}_{3}$ was used as internal standard $(\delta=77.0)$ and spectra were obtained with complete proton decoupling. For ${ }^{19} \mathrm{~F} \mathrm{NMR}$, $\mathrm{CFCl}_{3}$ was used as internal standard $(\delta=0)$. Column chromatography was performed on silica gel (230-400 mesh) and analytical thin-layer chromatography was carried out using $250 \mu \mathrm{m}$ commercial silica gel plates. Visualization of the developed chromatogram was performed by UV absorbance or aqueous potassium permanganate.

Typical Procedure for the Bismuth Triflate-Catalyzed Mukaiyama Aldol Reaction with Aromatic Aldehydes: To a solution of the aldehyde $(0.71 \mathrm{mmol})$ in diethyl ether $(0.5 \mathrm{~mL})$, was added $\mathrm{Bi}(\mathrm{OTf})_{3} \bullet 4 \mathrm{H}_{2} \mathrm{O}(0.007 \mathrm{mmol})$. The mixture was brought to $-78{ }^{\circ} \mathrm{C}$, stirred at this temperature for $0.25 \mathrm{~h}$, and a solution of 2-(trimethylsilyloxy)furan 2a $(0.85 \mathrm{mmol})$ in diethyl ether $(0.5 \mathrm{~mL})$ was added dropwise. The mixture was stirred at $-78{ }^{\circ} \mathrm{C}$ until the reaction was completed as indicated by TLC. The reaction was diluted with tetrahydrofuran $(1.0 \mathrm{~mL})$ and quenched with $10 \%$ aqueous $\mathrm{HCl}(1.0 \mathrm{~mL})$. The mixture was stirred for $0.25 \mathrm{~h}$ at room temperature, neutralized by addition of a saturated aqueous $\mathrm{NaHCO}_{3}$ solution, and extracted with ethyl acetate. The organic phases were combined, dried over $\mathrm{Na}_{2} \mathrm{SO}_{4}$ and concentrated under reduced pressure (rotary evaporator). The syn/anti ratio of the product was determined by ${ }^{1} \mathrm{H}$ NMR analysis of the crude reaction mixture. The relative configurations of the product was assigned according to the literature. ${ }^{1}$ The crude product was purified by silica gel chromatography (ethyl acetate/hexane). $\mathbf{3 a}, \mathbf{3 d}, \mathbf{3 e}, \mathbf{3 h}$, and $\mathbf{3 j}$ accord exactly with those that have been previously reported in the literature. ${ }^{1,2,3}$

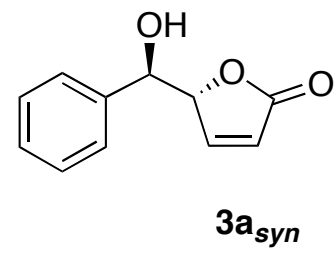

5-(Hydroxy(phenyl)methyl)furan-2(5H)-one (3a): ${ }^{1}$ Reagents: benzaldehyde (75 mg, $0.71 \mathrm{mmol}), 2$-(trimethylsilyloxy)furan $2 \mathrm{a}(133 \mathrm{mg}, 0.85 \mathrm{mmol})$, and $\mathrm{Bi}(\mathrm{OTf})_{3} \bullet 4 \mathrm{H}_{2} \mathrm{O}(5.0 \mathrm{mg}$, $0.007 \mathrm{mmol})$. The reaction was stirred for $0.5 \mathrm{~h}$ at $-78{ }^{\circ} \mathrm{C}$ and quenched according to the typical procedure. The syn/anti ratio (94:6) was determined by ${ }^{1} \mathrm{H}$ NMR analysis of the crude product $(\delta$ major: $4.71 \mathrm{ppm}, \delta$ minor: $5.10 \mathrm{ppm})$. The crude product was then purified on silica gel $(25 \%$ ethyl acetate/hexane) to afford $122 \mathrm{mg}(91 \%)$ of 3a as two separated diastereoisomers: $S y n$ diastereoisomer: $\mathrm{mp} 57{ }^{\circ} \mathrm{C}$ (white solid); $R_{f}=0.26$ (30\% ethyl acetate/hexane); ${ }^{1} \mathrm{H}$ NMR (400 $\left.\mathrm{MHz}_{\mathrm{CDCl}}\right): \delta=7.36-7.42(\mathrm{~m}, 5 \mathrm{H}), 7.18(\mathrm{dd}, J=5.8,1.6 \mathrm{~Hz}, 1 \mathrm{H}) 6.13(\mathrm{dd}, J=5.8,2.0 \mathrm{~Hz}$, $1 \mathrm{H}), 5.17(\mathrm{dt}, J=7.1,1.6 \mathrm{~Hz}, 1 \mathrm{H}), 4.71(\mathrm{~d}, J=7.1 \mathrm{~Hz}, 1 \mathrm{H}), 2.73($ br s, $1 \mathrm{H}) ;{ }^{13} \mathrm{C} \mathrm{NMR}(100 \mathrm{MHz}$, $\left.\mathrm{CDCl}_{3}\right): \delta=172.6,153.2,137.9,129.2,129.1,126.9,123.3,87.1,76.0$; IR (film): 3438, 
$1764 \mathrm{~cm}^{-1}$. Anti diastereoisomer: $R_{f}=0.28$ (30\% ethyl acetate/hexane); ${ }^{1} \mathrm{H}$ NMR (400 MHz, $\left.\mathrm{CDCl}_{3}\right): \delta=7.34-7.42(\mathrm{~m}, 6 \mathrm{H}), 6.20(\mathrm{dd}, J=5.8,2.0 \mathrm{~Hz}, 1 \mathrm{H}), 5.19(\mathrm{dt}, J=3.6,1.8 \mathrm{~Hz}, 1 \mathrm{H}), 5.10$ $(\mathrm{t}, J=4.2 \mathrm{~Hz}, 1 \mathrm{H}), 2.45$ (br s, $1 \mathrm{H}) ;{ }^{13} \mathrm{C} \mathrm{NMR}\left(100 \mathrm{MHz}, \mathrm{CDCl}_{3}\right): \delta=173.2,152.9,139.1,129.0$, 128.8, 126.3, 123.5, 86.7, 73.4. IR (film): $3438,1764 \mathrm{~cm}^{-1}$.

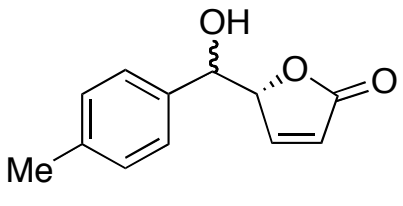

$3 \mathbf{b}$

5-(Hydroxy(4-tolyl)methyl)furan-2(5H)-one (3b): Reagents: $p$-tolualdehyde (85 $\mathrm{mg}$, $0.71 \mathrm{mmol}), 2$-(trimethylsilyloxy)furan $2 \mathrm{a}(133 \mathrm{mg}, 0.85 \mathrm{mmol})$, and $\mathrm{Bi}(\mathrm{OTf})_{3} \bullet 4 \mathrm{H}_{2} \mathrm{O}(5.0 \mathrm{mg}$, $0.007 \mathrm{mmol})$. The reaction was stirred for $1 \mathrm{~h}$ at $-78{ }^{\circ} \mathrm{C}$ and quenched according to the typical procedure. The syn/anti ratio (94:6) was determined by ${ }^{1} \mathrm{H}$ NMR analysis of the crude product $(\delta$ major: $4.66 \mathrm{ppm}, \delta$ minor: $5.03 \mathrm{ppm})$. The residue was purified by silica gel chromatography (25\% ethyl acetate/hexane) to afford $130 \mathrm{mg}(90 \%)$ of $\mathbf{3 b}$ as a mixture of unseparable diastereoisomers: $R_{f}=0.20$ (30\% ethyl acetate/hexane); ${ }^{1} \mathrm{H}$ NMR $\left(400 \mathrm{MHz}, \mathrm{CDCl}_{3}\right): \delta=7.37$ (dd, $J=5.8,1.6 \mathrm{~Hz}, 1 \mathrm{H}($ anti)), 7.25 (d, $J=7.6 \mathrm{~Hz}, 2 \mathrm{H}), 7.21$ (d, $J=7.6 \mathrm{~Hz}, 2 \mathrm{H}), 7.13$ (dd, $J=$ $5.9,1.6 \mathrm{~Hz}, 1 \mathrm{H}($ syn) ), 6.17 (dd, $J=5.9,2.0 \mathrm{~Hz}, 1 \mathrm{H}($ anti)), 6.12 (dd, $J=5.9,2.0 \mathrm{~Hz}, 1 \mathrm{H}(s y n))$, 5.13-5.16 (m, 2H), 5.03 (m, 1H (anti)), $4.66(\mathrm{~d}, J=7.2 \mathrm{~Hz}, 1 \mathrm{H}($ syn) ), 2.77 (br s, 1H), 2.36 (s, $3 \mathrm{H}) ; \mathrm{NMR}{ }^{13} \mathrm{C}\left(100 \mathrm{MHz}, \mathrm{CDCl}_{3}\right): \delta=172.6,153.4,139.1,134.9,129.7,126.9,123.2,87.2$, 75.8, 21.5; IR (KBr): 3411, $1742 \mathrm{~cm}^{-1}$; HRMS: Calcd for $\mathrm{C}_{12} \mathrm{H}_{12} \mathrm{O}_{3}\left(\mathrm{M}^{+}\right)$204.0786, found 204.0782 .<smiles>COc1ccc([C@@H](O)[C@H]2C=CC(=O)O2)cc1</smiles>

3d

5-(Hydroxy(4-methoxyphenyl)methyl)furan-2(5H)-one $\quad(3 \mathrm{~d}):^{2} \quad$ Reagents: $\quad p$ anisaldehyde (100 mg, $0.73 \mathrm{mmol}), 2$-(trimethylsilyloxy)furan $2 \mathbf{2 a}(138 \mathrm{mg}, 0.88 \mathrm{mmol})$, and $\mathrm{Bi}(\mathrm{OTf})_{3} \cdot 4 \mathrm{H}_{2} \mathrm{O}(5.0 \mathrm{mg}, 0.0072 \mathrm{mmol})$. The reaction was stirred at $-78{ }^{\circ} \mathrm{C}$ for $0.5 \mathrm{~h}$ and quenched according to the typical procedure. The syn/anti ratio (90:10) was determined by ${ }^{1} \mathrm{H}$ NMR analysis of the crude product ( $\delta$ major: $4.65 \mathrm{ppm}, \delta$ minor: $5.00 \mathrm{ppm}$ ). The crude product was then purified on silica gel (30\% to $50 \%$ ethyl acetate/hexane) to afford $136 \mathrm{mg}(84 \%)$ of $\mathbf{3 d}$ as a mixture of unseparable diastereoisomers: $R_{f}=0.25$ (40\% ethyl acetate/hexane); ${ }^{1} \mathrm{H}$ NMR $\left(400 \mathrm{MHz}, \mathrm{CDCl}_{3}\right): \delta=7.38(\mathrm{dd}, J=5.9,1.6 \mathrm{~Hz}, 1 \mathrm{H}($ anti) $), 7.30(\mathrm{~d}, J=8.4 \mathrm{~Hz}, 2 \mathrm{H}), 7.16(\mathrm{dd}, J$ $=5.9,1.6 \mathrm{~Hz}, 1 \mathrm{H}(s y n)), 6.91(\mathrm{~d}, J=8.4 \mathrm{~Hz}, 2 \mathrm{H}), 6.18(\mathrm{dd}, J=5.9,2.0 \mathrm{~Hz}, 1 \mathrm{H}($ anti) $), 6.12(\mathrm{dd}, J$ $=5.9,2.0 \mathrm{~Hz}, 1 \mathrm{H}($ syn $)), 5.15(\mathrm{dt}, J=6.8,1.2 \mathrm{~Hz}, 2 \mathrm{H}($ syn) $), 5.00(\mathrm{dd}, J=7.1,2.7 \mathrm{~Hz}, 1 \mathrm{H}($ anti)), $4.65(\mathrm{dd}, J=7.1,2.7 \mathrm{~Hz}, 1 \mathrm{H}(\mathrm{syn})), 3.82(\mathrm{~s}, 3 \mathrm{H}), 2.75$ (br s, $1 \mathrm{H}) ;{ }^{13} \mathrm{C} \mathrm{NMR}\left(100 \mathrm{MHz}, \mathrm{CDCl}_{3}\right): \delta$ $=172.8,160.2,153.4,153.2,129.9,128.3,127.6,123.4,123.2,114.4,87.3,86.8,75.5,73.2$, 55.6; IR (film): $3404,1751 \mathrm{~cm}^{-1}$. 


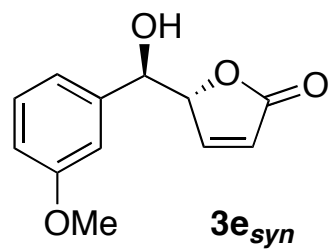

5-(Hydroxy(3-methoxyphenyl)methyl)furan-2(5H)-one $\quad$ (3e): ${ }^{3} \quad$ Reagents: $\quad m$ anisaldehyde (100 mg, $0.73 \mathrm{mmol})$, 2-(trimethylsilyloxy)furan $2 \mathrm{a}(138 \mathrm{mg}, 0.88 \mathrm{mmol})$, and $\mathrm{Bi}(\mathrm{OTf})_{3}{ }^{\circ} 4 \mathrm{H}_{2} \mathrm{O}(5.0 \mathrm{mg}, 0.0072 \mathrm{mmol})$. The reaction was stirred at $-78^{\circ} \mathrm{C}$ for $2 \mathrm{~h}$, then at $-45^{\circ} \mathrm{C}$ for $0.5 \mathrm{~h}$, and quenched according to the typical procedure. The syn/anti ratio (93:7) was determined by ${ }^{1} \mathrm{H}$ NMR analysis of the crude product ( $\delta$ major: $4.68 \mathrm{ppm}, \delta$ minor: $5.09 \mathrm{ppm}$ ). The residue was purified by silica gel chromatography ( $20 \%$ to $40 \%$ ethyl acetate/hexane) to afford $131 \mathrm{mg}$ (81\%) of $3 \mathbf{e}$ as the pure syn diastereoisomer (colorless oil): $R_{f}=0.20$ (50\% ethyl acetate/hexane); ${ }^{1} \mathrm{H}$ NMR (400 MHz, $\left.\mathrm{CDCl}_{3}\right): \delta=7.32(\mathrm{t}, J=8.1 \mathrm{~Hz}, 1 \mathrm{H}), 7.18(\mathrm{dd}, J=5.8,1.5$ $\mathrm{Hz}, 2 \mathrm{H}), 6.85-6.96(\mathrm{~m}, 3 \mathrm{H}), 6.13(\mathrm{dd}, J=5.8,2.0 \mathrm{~Hz}, 1 \mathrm{H}), 5.15-5.19(\mathrm{~m}, 2 \mathrm{H}), 4.68(\mathrm{~d}, J=7.2$ $\mathrm{Hz}, 1 \mathrm{H}), 3.83(\mathrm{~s}, 3 \mathrm{H}), 3.13($ br s, $1 \mathrm{H}) ;{ }^{13} \mathrm{C}$ NMR $\left(100 \mathrm{MHz}, \mathrm{CDCl}_{3}\right): \delta=172.9,160.1,153.6$, 139.7, 130.1, 123.1, 119.2, 114.1, 112.5, 87.2, 75.7, 55.6; IR (film): 3442, $1747 \mathrm{~cm}^{-1}$.<smiles>O=C1C=C[C@@H]([C@@H](O)c2ccc(Cl)cc2)O1</smiles>

$3 f$

5-(Hydroxy(4-chlorophenyl)methyl)furan-2(5H)-one (3f): Reagents: 4-chlorobenzaldehyde (100 mg, $0.71 \mathrm{mmol})$, 2-(trimethylsilyloxy)furan 2 a $(133 \mathrm{mg}, 0.85 \mathrm{mmol})$, and $\mathrm{Bi}(\mathrm{OTf})_{3}{ }^{\bullet} 4 \mathrm{H}_{2} \mathrm{O}(5.0 \mathrm{mg}, 0.0072 \mathrm{mmol})$. The reaction was stirred for $0.5 \mathrm{~h}$ at $-78{ }^{\circ} \mathrm{C}$ and quenched according to the typical procedure. The syn/anti ratio (93:7) was determined by ${ }^{1} \mathrm{H}$ NMR analysis of the crude product ( $\delta$ major: $4.75 \mathrm{ppm}, \delta$ minor: $5.06 \mathrm{ppm})$. The residue was purified by flash chromatography (30\% ethyl acetate/hexane) to afford $144 \mathrm{mg}(90 \%)$ of $\mathbf{3 f}$ as a mixture of unseparable diastereoisomers: $R_{f}=0.17$ (30\% ethyl acetate/hexane); ${ }^{1} \mathrm{H}$ NMR $(400$ $\left.\mathrm{MHz}, \mathrm{CDCl}_{3}\right): \delta=7.36(\mathrm{~d}, J=2.0 \mathrm{~Hz}, 2 \mathrm{H}), 7.33(\mathrm{~d}, J=2.0 \mathrm{~Hz}, 2 \mathrm{H}), 7.20(\mathrm{dd}, J=5.8,1.6 \mathrm{~Hz}$, $1 \mathrm{H}), 6.13(\mathrm{dd}, J=5.9,2.1 \mathrm{~Hz}, 1 \mathrm{H}), 5.13-5.16(\mathrm{~m}, 2 \mathrm{H}), 4.75(\mathrm{~d}, J=6.7 \mathrm{~Hz}, 1 \mathrm{H}) ;{ }^{13} \mathrm{C}$ NMR $(100$ $\left.\mathrm{MHz}, \mathrm{CDCl}_{3}\right): \delta=172.5,152.9,136.4,135.0,129.2,128.4,123.5,86.6,74.9 ; \mathrm{IR}(\mathrm{KBr}): 3440$, $1766 \mathrm{~cm}^{-1}$; HRMS: Calcd for $\mathrm{C}_{11} \mathrm{H}_{9} \mathrm{ClO}_{3}\left(\mathrm{M}^{+}\right)$224.0240, found 224.0236. 


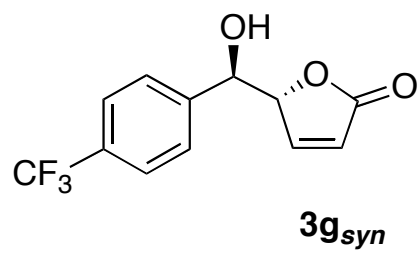

5-(Hydroxy(4-trifluoromethylphenyl)methyl)furan-2(5H)-one (3g): Reagents: $\alpha, \alpha, \alpha-$ trifluoro- $p$-tolualdehyde (125 mg, $0.718 \mathrm{mmol})$, 2-(trimethylsilyloxy)furan 2a (135 mg, 0.861 $\mathrm{mmol})$, and $\mathrm{Bi}(\mathrm{OTf})_{3} \bullet 4 \mathrm{H}_{2} \mathrm{O}(10.0 \mathrm{mg}, 0.014 \mathrm{mmol})$. The reaction was stirred for $0.5 \mathrm{~h}$ at $-45{ }^{\circ} \mathrm{C}$ and quenched according to the typical procedure. The syn/anti ratio ( $>98: 2)$ was determined by ${ }^{1} \mathrm{H}$ NMR analysis of the crude product. The residue was purified by flash chromatography (40\% ethyl acetate/hexane) to afford $120 \mathrm{mg}(65 \%)$ of $\mathbf{3 g}$ as the pure syn diastereoisomer (colorless oil): $R_{f}=0.13\left(30 \%\right.$ ethyl acetate/hexane); ${ }^{1} \mathrm{H} \mathrm{NMR}\left(400 \mathrm{MHz}, \mathrm{CDCl}_{3}\right): \delta=7.88(\mathrm{~d}, J=7.8 \mathrm{~Hz}$, $1 \mathrm{H}), 7.72(\mathrm{~d}, J=7.8 \mathrm{~Hz}, 1 \mathrm{H}), 7.67(\mathrm{t}, J=7.6 \mathrm{~Hz}, 1 \mathrm{H}), 7.52(\mathrm{t}, J=7.6 \mathrm{~Hz}, 1 \mathrm{H}), 7.12-7.14(\mathrm{~m}$, $1 \mathrm{H}), 6.20(\mathrm{dd}, J=5.7,2.0 \mathrm{~Hz}, 1 \mathrm{H}), 5.19-5.21(\mathrm{~m}, 2 \mathrm{H}), 5.14(\mathrm{~d}, J=5.9 \mathrm{~Hz}, 1 \mathrm{H}), 2.99$ (br s, 1H); ${ }^{13} \mathrm{C}$ NMR $\left(100 \mathrm{MHz}, \mathrm{CDCl}_{3}\right): \delta=173.1,152.9,132.8,129.2,127.5(\mathrm{q}, J=29.8 \mathrm{~Hz}), 126.0(\mathrm{q}, J$ $=6.1 \mathrm{~Hz}), 124.2(\mathrm{q}, J=273.8 \mathrm{~Hz}), 123.3,86.9,69.9 ;{ }^{19} \mathrm{~F} \mathrm{NMR}\left(376 \mathrm{MHz}, \mathrm{CDCl}_{3}\right): \delta=-57.84$; IR (film) 3443, $1751 \mathrm{~cm}^{-1}$; HRMS: Calcd for $\mathrm{C}_{12} \mathrm{H}_{9} \mathrm{~F}_{3} \mathrm{O}_{3}(\mathrm{M}+\mathrm{H})^{+}$259.0582, found 259.0577 .

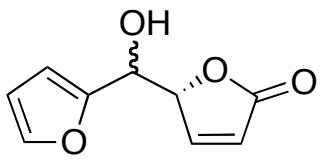

3h

5-((Furan-2-yl)(hydroxy)methyl)furan-2(5H)-one (3h): ${ }^{2}$ Reagents: 2-furaldehyde (70 $\mathrm{mg}, 0.73 \mathrm{mmol})$, 2-(trimethylsilyloxy)furan $2 \mathrm{a}(137 \mathrm{mg}, 0.87 \mathrm{mmol})$, and $\mathrm{Bi}(\mathrm{OTf})_{3} \bullet 4 \mathrm{H}_{2} \mathrm{O}(5.0$ $\mathrm{mg}, 0.0072 \mathrm{mmol})$. The reaction was stirred at $-78{ }^{\circ} \mathrm{C}$ for $0.15 \mathrm{~h}$, then at $-45{ }^{\circ} \mathrm{C}$ for $0.5 \mathrm{~h}$, and quenched with sat. aqueous $\mathrm{NH}_{4} \mathrm{Cl}(1 \mathrm{~mL})$. The mixture was then treated according to the typical procedure. The syn/anti ratio $(72: 28)$ was determined by ${ }^{1} \mathrm{H}$ NMR analysis of the crude product ( $\delta$ major: $4.80 \mathrm{ppm}, \delta$ minor: $5.03 \mathrm{ppm}$ ). The residue was purified by silica gel chromatography (20\% ethyl acetate/hexane) to afford $113 \mathrm{mg}(86 \%)$ of $\mathbf{3 h}$ as a mixture of unseparable diastereoisomers: $R_{f}=0.22$ (25\% ethyl acetate/hexane); ${ }^{1} \mathrm{H}$ NMR $\left(400 \mathrm{MHz}, \mathrm{CDCl}_{3}\right): \delta=7.57$ (dd, $J=5.7,1.6 \mathrm{~Hz}, 1 \mathrm{H}($ anti)), $7.42(\mathrm{~s}, 1 \mathrm{H}), 7.35$ (dd, $J=5.8,1.5 \mathrm{~Hz}, 1 \mathrm{H}($ syn)), 6.44 (dd, $J=$ $5.8,1.6 \mathrm{~Hz}, 1 \mathrm{H}), 6.38-6.42(\mathrm{~m}, 1 \mathrm{H}), 6.22(\mathrm{dd}, J=5.9,2.0 \mathrm{~Hz}, 1 \mathrm{H}($ anti) $) 6.18$ (dd, $J=5.9,2.0$ $\mathrm{Hz}, 1 \mathrm{H}($ syn) ), 5.32-5.35 (m, 2H), $5.03(\mathrm{~d}, J=4.7 \mathrm{~Hz}, 1 \mathrm{H}($ anti) $), 4.80(\mathrm{~d}, J=6.1 \mathrm{~Hz}, 1 \mathrm{H}($ syn)), 2.74 (br s, $1 \mathrm{H}) ;{ }^{13} \mathrm{C}$ NMR $\left(100 \mathrm{MHz}, \mathrm{CDCl}_{3}\right): \delta=172.9,153.5,153.3,151.6,151.3,143.1$, 123.2, 110.9, 108.9, 108.7, 85.2, 84.7, 69.1, 67.9; IR (film): $3382,1755 \mathrm{~cm}^{-1}$. 


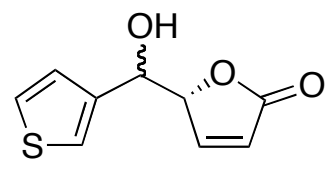

$3 \mathbf{i}$

5-(Hydroxy(3-thiophenyl)methyl)furan-2(5H)-one (3i): Reagents: 3-thiophenecarboxaldehyde (80 mg, $0.71 \mathrm{mmol})$, 2-(trimethylsilyloxy)furan $2 \mathbf{a}(134 \mathrm{mg}, 0.85 \mathrm{mmol})$, and $\mathrm{Bi}(\mathrm{OTf})_{3} \bullet 4 \mathrm{H}_{2} \mathrm{O}(5.0 \mathrm{mg}, 0.0071 \mathrm{mmol})$. The reaction was stirred for $0.25 \mathrm{~h}$ at $-78{ }^{\circ} \mathrm{C}$ and quenched according to the typical procedure. The syn/anti ratio $(80: 20)$ was determined by ${ }^{1} \mathrm{H}$ NMR analysis of the crude product ( $\delta$ major: $4.87 \mathrm{ppm}, \delta$ minor: $5.16 \mathrm{ppm}$ ). The residue was purified by silica gel chromatography (30\% to 50\% ethyl acetate/hexane) to afford $127 \mathrm{mg}(85 \%)$ of $3 \mathbf{i}$ as a mixture of unseparable diastereoisomers: $R_{f}=0.15\left(30 \%\right.$ ethyl acetate/hexane); ${ }^{1} \mathrm{H}$ NMR (400 MHz, $\left.\mathrm{CDCl}_{3}\right) \delta=7.34-7.37(\mathrm{~m}, 2 \mathrm{H}), 7.26(\mathrm{~m}, 1 \mathrm{H}), 7.12(\mathrm{dd}, J=6.2,1.5 \mathrm{~Hz}, 1 \mathrm{H})$, $6.15(\mathrm{dd}, J=5.7,2.0 \mathrm{~Hz}, 1 \mathrm{H}), 5.22(\mathrm{~m}, 2 \mathrm{H}), 4.87(\mathrm{~d}, J=6.4 \mathrm{~Hz}, 1 \mathrm{H}), 2.42(\mathrm{br} \mathrm{s}, 1 \mathrm{H}) ;{ }^{13} \mathrm{C} \mathrm{NMR}$ $\left(100 \mathrm{MHz}, \mathrm{CDCl}_{3}\right): \delta=172.8,153.5,139.5,127.0,126.1,123.4,123.3,86.5,71.6$; IR (KBr): 3491, $1780 \mathrm{~cm}^{-1}$; HRMS: Calcd for $\mathrm{C}_{9} \mathrm{H}_{8} \mathrm{O}_{3} \mathrm{~S}\left(\mathrm{M}^{+}\right)$196.0194, found 196.0199.

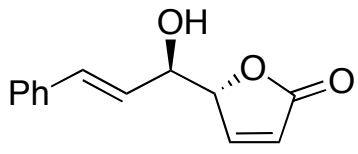

\section{$3 \mathbf{j}_{\text {syn }}$}

5-((E)-1-Hydroxy-3-phenylallyl)furan-2(5H)-one $\quad(3 \mathbf{j}):^{2} \quad$ Reagents: ${ }^{2}$ transcinnamaldehyde (95 mg, $0.71 \mathrm{mmol})$, 2-(trimethylsilyloxy)furan $\mathbf{2 a}(135 \mathrm{mg}, 0.86 \mathrm{mmol}$ ), and $\mathrm{Bi}(\mathrm{OTf})_{3} \bullet 4 \mathrm{H}_{2} \mathrm{O}(5.0 \mathrm{mg}, 0.0072 \mathrm{mmol})$. The reaction was stirred at $-78{ }^{\circ} \mathrm{C}$ for $0.15 \mathrm{~h}$ and quenched according to the typical procedure. The syn/anti ratio (70:30) was determined by ${ }^{1} \mathrm{H}$ NMR analysis of the crude product ( $\delta$ major: $4.43 \mathrm{ppm}, \delta$ minor: $4.65 \mathrm{ppm}$ ). The crude product was then purified on silica gel (20\% ethyl acetate/hexane) to afford $119 \mathrm{mg}(80 \%)$ of $\mathbf{3 j}$ as the pure syn diastereoisomer (white solid): mp $128{ }^{\circ} \mathrm{C} ; R_{f}=0.32\left(40 \%\right.$ ethyl acetate/hexane); ${ }^{1} \mathrm{H}$ NMR (400 MHz, $\left.\mathrm{CDCl}_{3}\right): \delta=7.46(\mathrm{dd}, J=5.8,1.5 \mathrm{~Hz}, 1 \mathrm{H}) ; 7.26-7.42(\mathrm{~m}, 5 \mathrm{H}), 6.76(\mathrm{~d}, J=16.0$ $\mathrm{Hz}, 1 \mathrm{H}), 6.20(\mathrm{dd}, J=5.5,1.9 \mathrm{~Hz}, 2 \mathrm{H}), 6.15(\mathrm{~d}, J=7.1 \mathrm{~Hz}, 1 \mathrm{H}), 5.08(\mathrm{dt}, J=5.8,1.7 \mathrm{~Hz}, 1 \mathrm{H})$, $4.42(\mathrm{t}, J=7.1 \mathrm{~Hz}, 1 \mathrm{H}), 1.92($ br s, $1 \mathrm{H}) ;{ }^{13} \mathrm{C}$ NMR $\left(100 \mathrm{MHz}, \mathrm{CDCl}_{3}\right): \delta=172.8,153.4,135.8$, 134.8, 128.9, 128.7, 126.9, 125.2, 123.4, 86.1, 73.8; IR (film): $3413,1751 \mathrm{~cm}^{-1}$.

Typical Procedure for the Bismuth-Catalyzed Mukaiyama Aldol Reaction with Aliphatic Aldehydes and Ketones: To a solution of $\mathrm{Bi}(\mathrm{OTf})_{3} \cdot 4 \mathrm{H}_{2} \mathrm{O}(0.036 \mathrm{mmol})$ and the aldehyde or ketone $(0.71 \mathrm{mmol})$ in diethyl ether $(0.5 \mathrm{~mL})$ at $-45^{\circ} \mathrm{C}$, was added dropwise a solution of 2-(trimethylsilyloxy)furan $\mathbf{2 a}(1.1 \mathrm{mmol})$ in diethyl ether $(0.5 \mathrm{~mL})$. The mixture was stirred at $-45^{\circ} \mathrm{C}$ for $3 \mathrm{~h}$. The reaction was diluted with tetrahydrofuran $(1.0 \mathrm{~mL})$ and quenched with $10 \%$ aqueous $\mathrm{HCl}(1.0 \mathrm{~mL})$. The biphasic sytem was stirred for $0.25 \mathrm{~h}$ at room temperature, neutralized by addition of $\mathrm{NaHCO}_{3}$ saturated solution, and extracted with ethyl acetate. The organic phases were combined, dried over $\mathrm{Na}_{2} \mathrm{SO}_{4}$, and concentrated under reduced pressure 
(rotary evaporator). Syn/anti ratios of the products were determined by ${ }^{1} \mathrm{H}$ NMR analysis of the crude reaction mixtures. The relative configurations of the products were assigned according to the literature. ${ }^{1,5}$ The crude products were purified by silica gel chromatography (ethyl acetate/hexane). 3k, 31, 3n, and 3n' accord exactly with those that have been previously reported in the literature. ${ }^{1,4,5}$

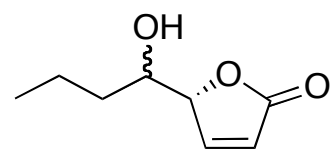

3k

5-(1-Hydroxybutyl)furan-2(5H)one (3k): ${ }^{4}$ Reagents: butyraldehyde (52 $\mathrm{mg}, 0.72$ mmol), 2-(trimethylsilyloxy)furan $2 \mathbf{2 a}(135 \mathrm{mg}, 0.87 \mathrm{mmol})$, and $\mathrm{Bi}(\mathrm{OTf})_{3} \bullet 4 \mathrm{H}_{2} \mathrm{O}(25 \mathrm{mg}, 0.036$ mmol). The reaction was stirred for $3 \mathrm{~h}$ at $-45{ }^{\circ} \mathrm{C}$ and quenched according to the typical procedure. The syn/anti ratio (70:30) was determined by ${ }^{1} \mathrm{H}$ NMR analysis of the crude product ( $\delta$ major: 3.90 ppm, $\delta$ minor: $4.97 \mathrm{ppm})$. The crude product was then purified on silica gel $(40 \%$ ethyl acetate/hexane) to afford $34 \mathrm{mg}(30 \%)$ of $\mathbf{3 k}$ as a mixture of unseparable diastereoisomers: $R_{f}=0.23$ (40\% ethyl acetate/hexane); ${ }^{1} \mathrm{H} \mathrm{NMR}\left(400 \mathrm{MHz}, \mathrm{CDCl}_{3}\right): \delta=7.55(\mathrm{dd}, J=5.8,1.6 \mathrm{~Hz}$, $1 \mathrm{H}($ anti) $), 7.48(\mathrm{dd}, J=5.8,1.6 \mathrm{~Hz}, 1 \mathrm{H}(s y n)), 6.20(\mathrm{dd}, J=5.6,2.0 \mathrm{~Hz}, 1 \mathrm{H}($ anti) $), 6.17(\mathrm{dd}, J=$ 5.6, $2.0 \mathrm{~Hz}, 1 \mathrm{H}($ syn) ), 4.99 (ddd, $J=4.5,2.0,1.5 \mathrm{~Hz}, 1 \mathrm{H}($ anti)), 4.97 (ddd, $J=4.5,2.0,1.5 \mathrm{~Hz}$, 1H (syn)), 3.90 (m, 1H (anti)), 3.78 (m, 1H (syn)), 2.00 (br s, 1H), 1.30-1.80 (m, 4H), 0.95 (m, $3 \mathrm{H}) ;{ }^{13} \mathrm{C}$ NMR $\left(100 \mathrm{MHz}, \mathrm{CDCl}_{3}\right): \delta=173.2,153.9,153.7,153.6,123.1,122.9,86.4,86.3,71.8$, 71.5, 35.5, 35.3, 19.0, 18.9, 14.1; IR (KBr): 3404, $1752 \mathrm{~cm}^{-1}$.

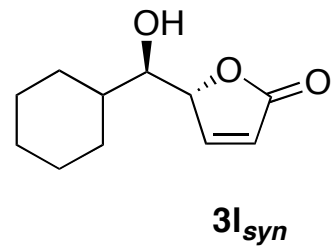

5-(cyclohexyl(hydroxy)methyl)furan-2(5H)one (31): ${ }^{1}$ Reagents: cyclohexanecarboxaldehyde (80 mg, $0.71 \mathrm{mmol})$, 2-(trimethylsilyloxy)furan 2a (167 mg, $1.1 \mathrm{mmol})$, and $\mathrm{Bi}(\mathrm{OTf})_{3} \bullet 4 \mathrm{H}_{2} \mathrm{O}(10 \mathrm{mg}, 0.014 \mathrm{mmol})$. The reaction was stirred at $-45{ }^{\circ} \mathrm{C}$ for $0.5 \mathrm{~h}$ and quenched according to the typical procedure. The syn/anti ratio $(75: 25)$ was determined by ${ }^{1} \mathrm{H}$ NMR analysis of the crude product ( $\delta$ major: $3.47 \mathrm{ppm}, \delta$ minor: $3.60 \mathrm{ppm}$ ). The crude product was then purified on silica gel (20\% ethyl acetate/hexane) to afford $35 \mathrm{mg}(25 \%)$ of 31 as the pure syn diastereoisomer (white solid): $\mathrm{mp} 103{ }^{\circ} \mathrm{C} ; R_{f}=0.23$ (30\% ethyl acetate/hexane); ${ }^{1} \mathrm{H}$ NMR (400 $\left.\mathrm{MHz}, \mathrm{CDCl}_{3}\right): \delta=7.45(\mathrm{dd}, J=5.8,1.6 \mathrm{~Hz}, 1 \mathrm{H}), 6.17(\mathrm{dd}, J=5.6,2.0 \mathrm{~Hz}, 1 \mathrm{H}), 5.18(\mathrm{ddd}, J=$ 1.8, 3.7, $1.8 \mathrm{~Hz}, 1 \mathrm{H}), 5.00$ (br s, 1H), 3.47 (dd, $J=6.7,3.7 \mathrm{~Hz}, 1 \mathrm{H}), 1.95(\mathrm{~m}, 1 \mathrm{H}), 1.79$ (m, 2H), $1.70(\mathrm{~m}, 1 \mathrm{H}), 1.60(\mathrm{~m}, 2 \mathrm{H}), 1.09-1.34(\mathrm{~m}, 6 \mathrm{H}) ;{ }^{13} \mathrm{C} \mathrm{NMR}\left(100 \mathrm{MHz}, \mathrm{CDCl}_{3}\right): \delta=173.3,154.7$, 122.5, 84.1, 75.6, 41.1, 29.4, 28.4, 26.0; IR (film): $3491,1760 \mathrm{~cm}^{-1}$. 


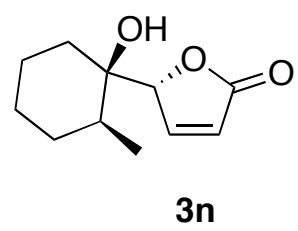

5-(1-Hydroxy-2-methylcyclohexyl)furan-2(5H)-one $\quad(3 \mathrm{n}):^{5} \quad$ Reagents: 2 methylcyclohexanone ( $80 \mathrm{mg}, 0.71 \mathrm{mmol}), 2$-(trimethylsilyloxy)furan 2a (167 mg, $1.1 \mathrm{mmol})$, and $\mathrm{Bi}(\mathrm{OTf})_{3} \bullet 4 \mathrm{H}_{2} \mathrm{O}(25 \mathrm{mg}, 0.036 \mathrm{mmol})$. The mixture was stirred at $-45{ }^{\circ} \mathrm{C}$ for $3 \mathrm{~h}$, then quenched according to the typical procedure. The diastereoisomeric ratio $(82: 7: 7: 4)$ was determined by ${ }^{1} \mathrm{H}$ NMR analysis of the crude product. The crude product was then purified on silica gel (20\% ethyl acetate/hexane) to afford $91 \mathrm{mg}(65 \%)$ of $\mathbf{3 n}$ as a single diastereoisomer (white solid): $\mathrm{mp} 110{ }^{\circ} \mathrm{C} ; R_{f}=0.19$ (30\% ethyl acetate/hexane); ${ }^{1} \mathrm{H}$ NMR $\left(400 \mathrm{MHz}, \mathrm{CDCl}_{3}\right): \delta=$ $7.44(\mathrm{dd}, J=5.8,1.6 \mathrm{~Hz}, 1 \mathrm{H}), 6.14(\mathrm{dd}, J=5.9,2.0 \mathrm{~Hz}, 1 \mathrm{H}), 5.20(\mathrm{t}, J=1.4 \mathrm{~Hz}, 1 \mathrm{H}), 1.89$ (br s, $1 \mathrm{H}), 1.39-1.70(\mathrm{~m}, 7 \mathrm{H}), 1.13-1.27(\mathrm{~m}, 1 \mathrm{H}), 1.04(\mathrm{~d}, J=6.3 \mathrm{~Hz}, 3 \mathrm{H}), 0.98-1.03(\mathrm{~m}, 1 \mathrm{H}) ;{ }^{13} \mathrm{C}$ NMR $\left(100 \mathrm{MHz}, \mathrm{CDCl}_{3}\right): \delta=173.2,153.0,122.9,88.9,74.8,37.7,31.4,30.5,25.6,20.8,15.7$; IR (KBr): 3469, $1771 \mathrm{~cm}^{-1}$; HRMS: Calcd for $\mathrm{C}_{11} \mathrm{H}_{16} \mathrm{O}_{3}(\mathrm{M}+\mathrm{H})^{+}$197.1178, found 197.1172.

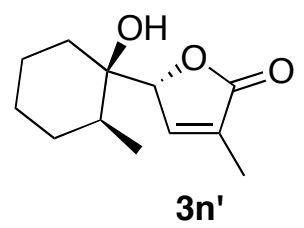

5-(1-Hydroxy-2-methylcyclohexyl)-3-methylfuran-2(5H)-one $\quad\left(3 \mathbf{n}^{\prime}\right):^{5} \quad$ Reagents: 2methylcyclohexanone (56 mg, $0.5 \mathrm{mmol}$ ), 3-methyl-2-(trimethylsilyloxy)furan $\mathbf{2 b}$ (128 mg, 0.75 $\mathrm{mmol})$, and $\mathrm{Bi}(\mathrm{OTf})_{3} \bullet 4 \mathrm{H}_{2} \mathrm{O}(18 \mathrm{mg}, 0.025 \mathrm{mmol})$. The reaction mixture was stirred at $-45^{\circ} \mathrm{C}$ for $3 \mathrm{~h}$, then at $0{ }^{\circ} \mathrm{C}$ for 1 extra h. The mixture was brought back to room temperature and quenched according to the typical procedure. The syn/anti ratios were determined by ${ }^{1} \mathrm{H}$ NMR analysis of the crude mixture: $\operatorname{anti}(R)-5-(1 R, 2 S) / \operatorname{syn}(S)-5-(1 R, 2 S) /(\operatorname{anti}(R)-5-(1 R, 2 R)+\operatorname{syn}(S)-5-(1 R, 2 R))=$ 73:10: $(9+8)$. The crude product was purified on silica gel $(2 \%$ ethyl acetate/hexane $)$ to afford $81 \mathrm{mg}(78 \%)$ of $3 \mathrm{n}$ ' as a single diastereoisomer (colorless solid): $\mathrm{mp} 80-84{ }^{\circ} \mathrm{C} ; R_{f}=0.21(20 \%$ ethyl acetate/hexane); ${ }^{1} \mathrm{H}$ NMR $\left(400 \mathrm{MHz} \mathrm{CDCl}_{3}\right): \delta=7.02(\mathrm{dq}, J=1.7,1.7 \mathrm{~Hz}, 1 \mathrm{H}), 5.10(\mathrm{dq}, J$ $=1.7,1.7 \mathrm{~Hz}, 1 \mathrm{H}), 1.95(\mathrm{dd}, J=1.7,1.7 \mathrm{~Hz}, 3 \mathrm{H}), 1.77($ br s, $1 \mathrm{H}), 1.67(\mathrm{~m}, 1 \mathrm{H}), 1.36-1.56(\mathrm{~m}$, $7 \mathrm{H}), 1.16(\mathrm{~m}, 1 \mathrm{H}), 1.09(\mathrm{~d}, J=6.4 \mathrm{~Hz}, 3 \mathrm{H}) ;{ }^{13} \mathrm{C} \mathrm{NMR}\left(100 \mathrm{MHz}, \mathrm{CDCl}_{3}\right): \delta=174.9,145.2$, $131.5,86.5,74.7,37.7,31.3,30.5,25.7,20.8,15.7,11.0$; IR (KBr): $3469,1771 \mathrm{~cm}^{-1}$.

\section{References}

(1) Szlosek, M; Figadère, B. Angew. Chem., Int. Ed. 2000, 39, 1799-1801.

(2) Acocella, M. R.; De Rosa, M.; Massa, A.; Palombi, L.; Villano, R.; Scettri, A. Tetrahedron 2005, 61, 4091-4097.

(3) Pohmakotr, M.; Tuchinda, P.; Premkaisorn, P.; Reutrakul, V. Tetrahedron 1998, 54, 11297-11304.

(4) Hjelmgaard, T.; Persson, T.; Rasmussen, T. B.; Givskov, M.; Nielsen, J. Bioorg. Med. Chem. 2003, i1, 3261-3271.

(5) Kong, K.; Romo, D. Org. Lett. 2006, 8, 2909-2912. 


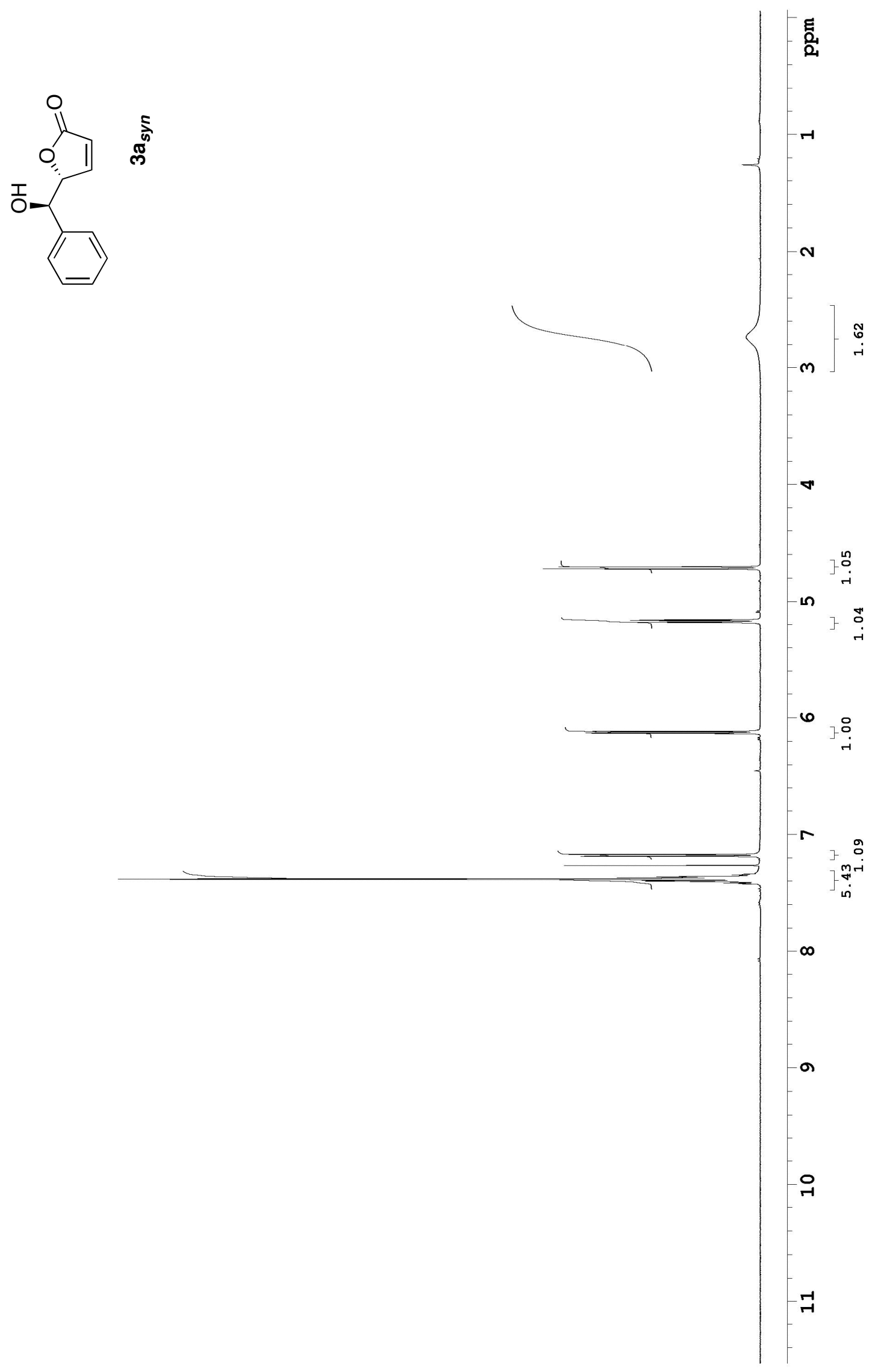




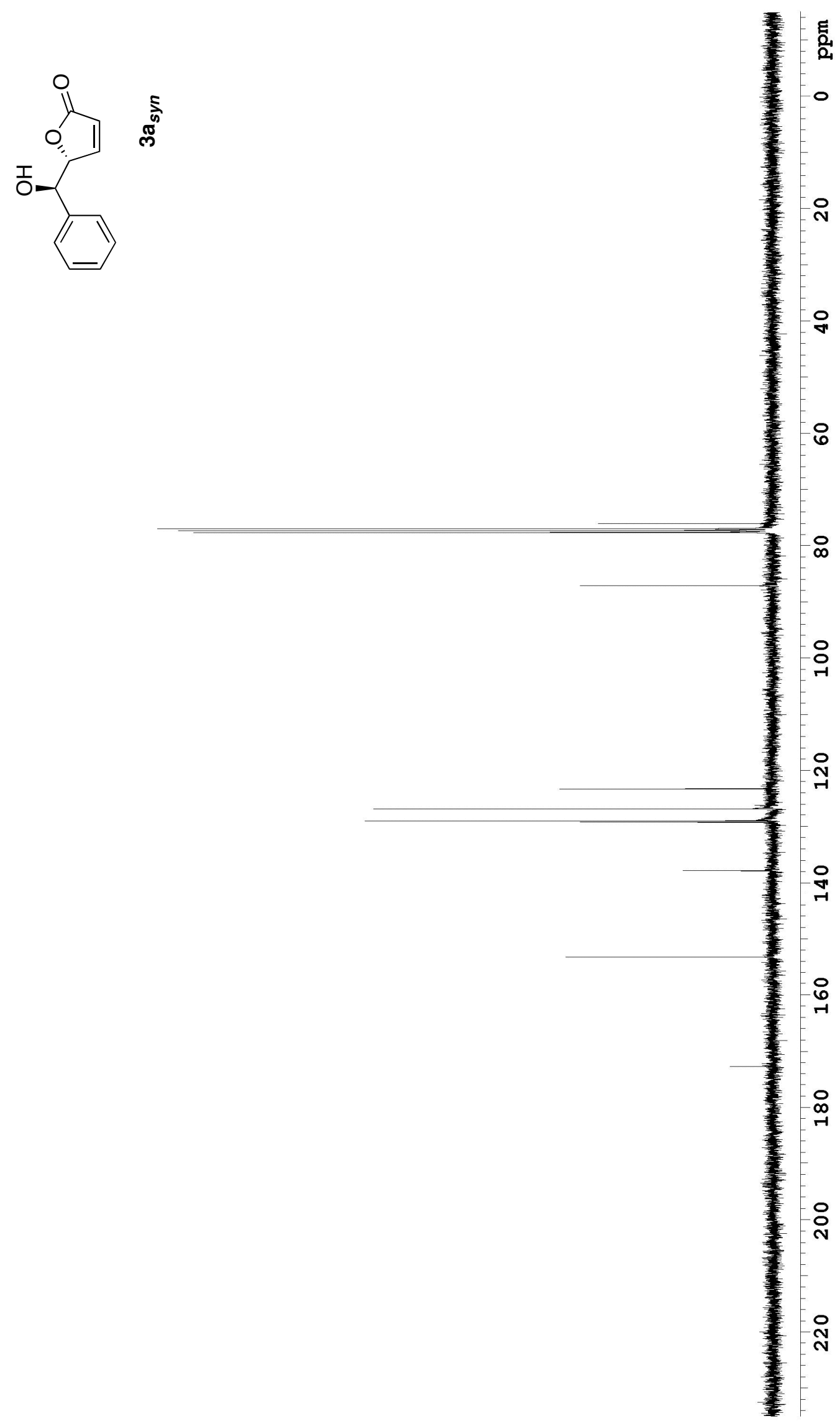

S-10 

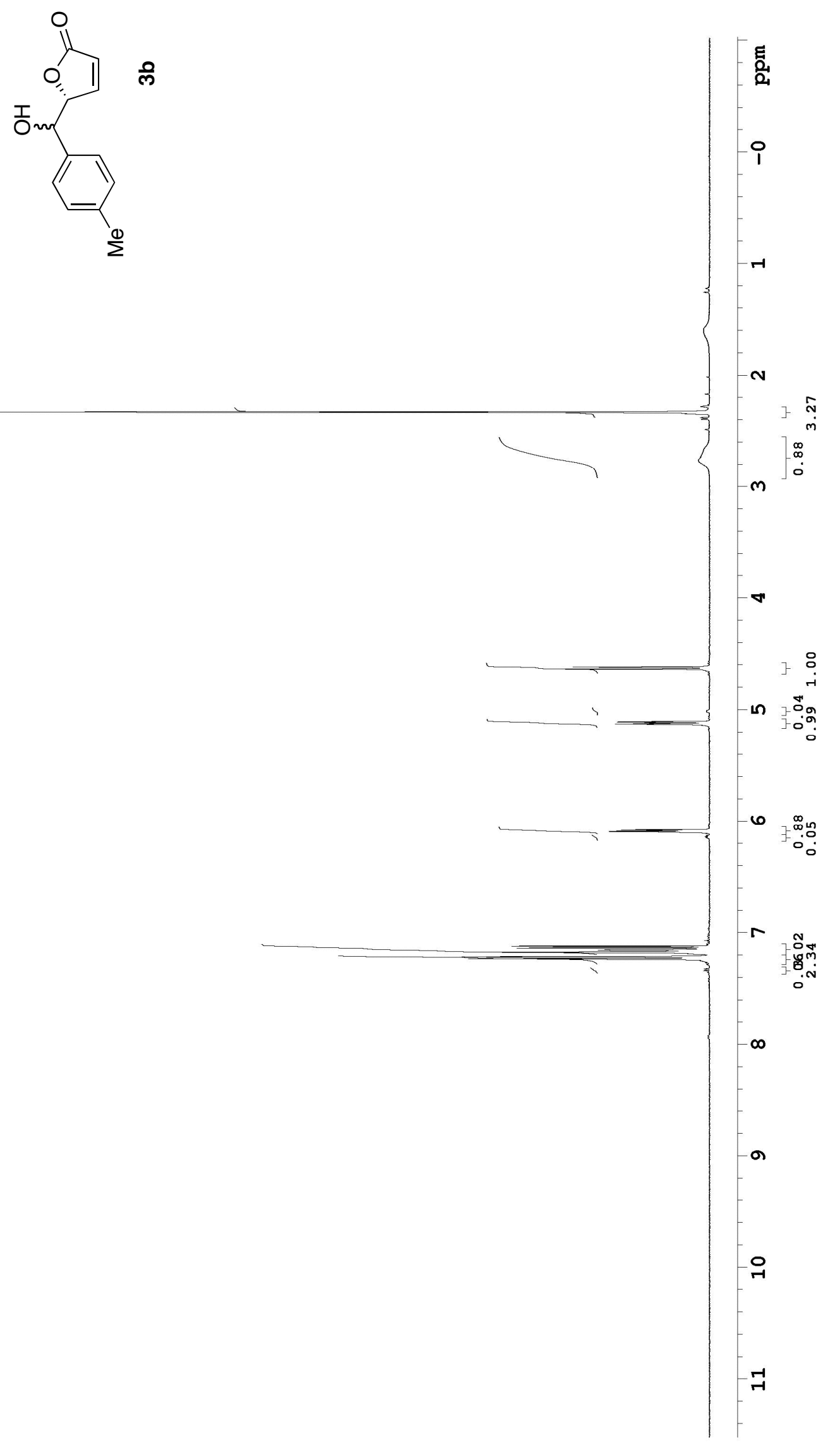

S-11 

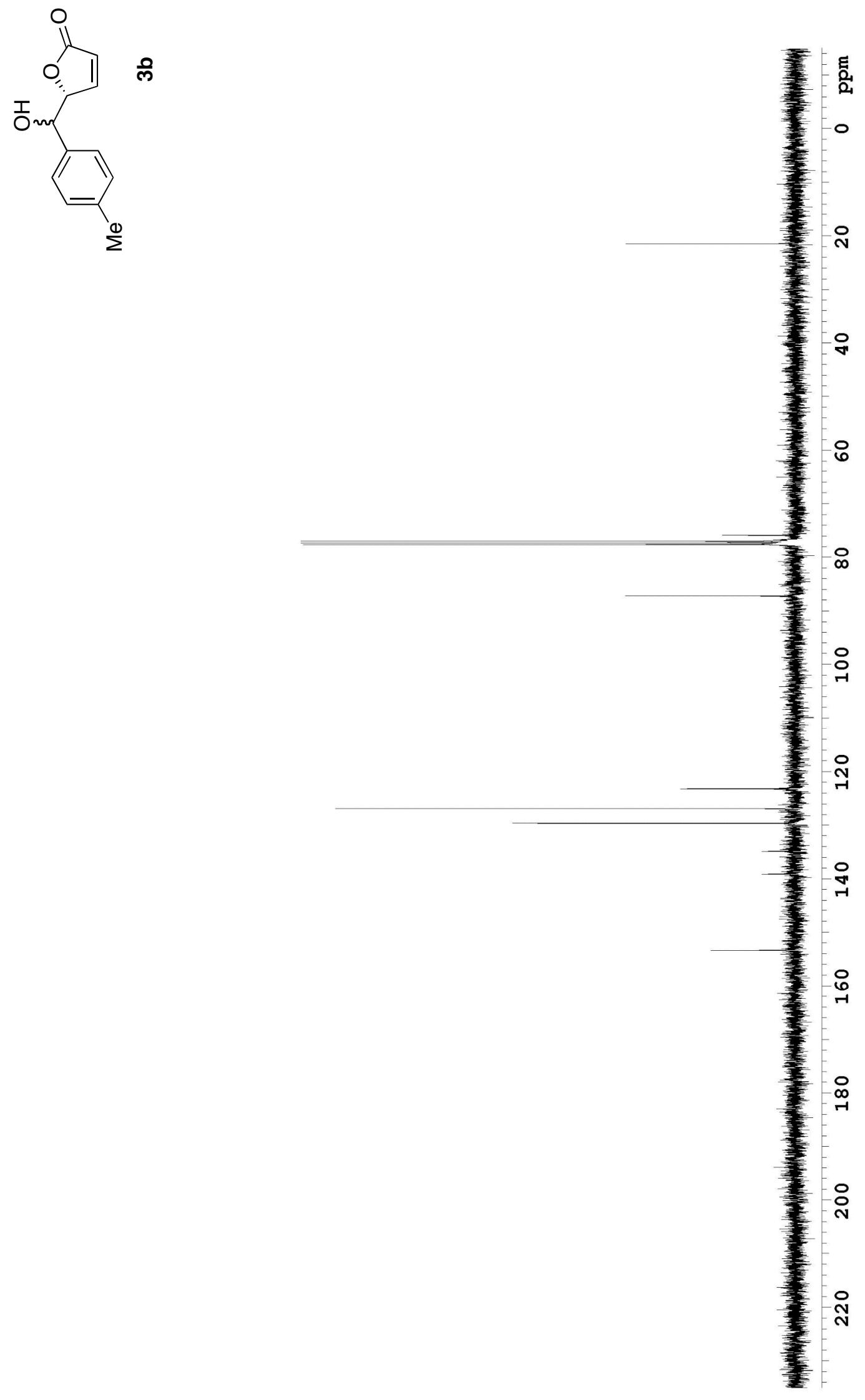

S-12 

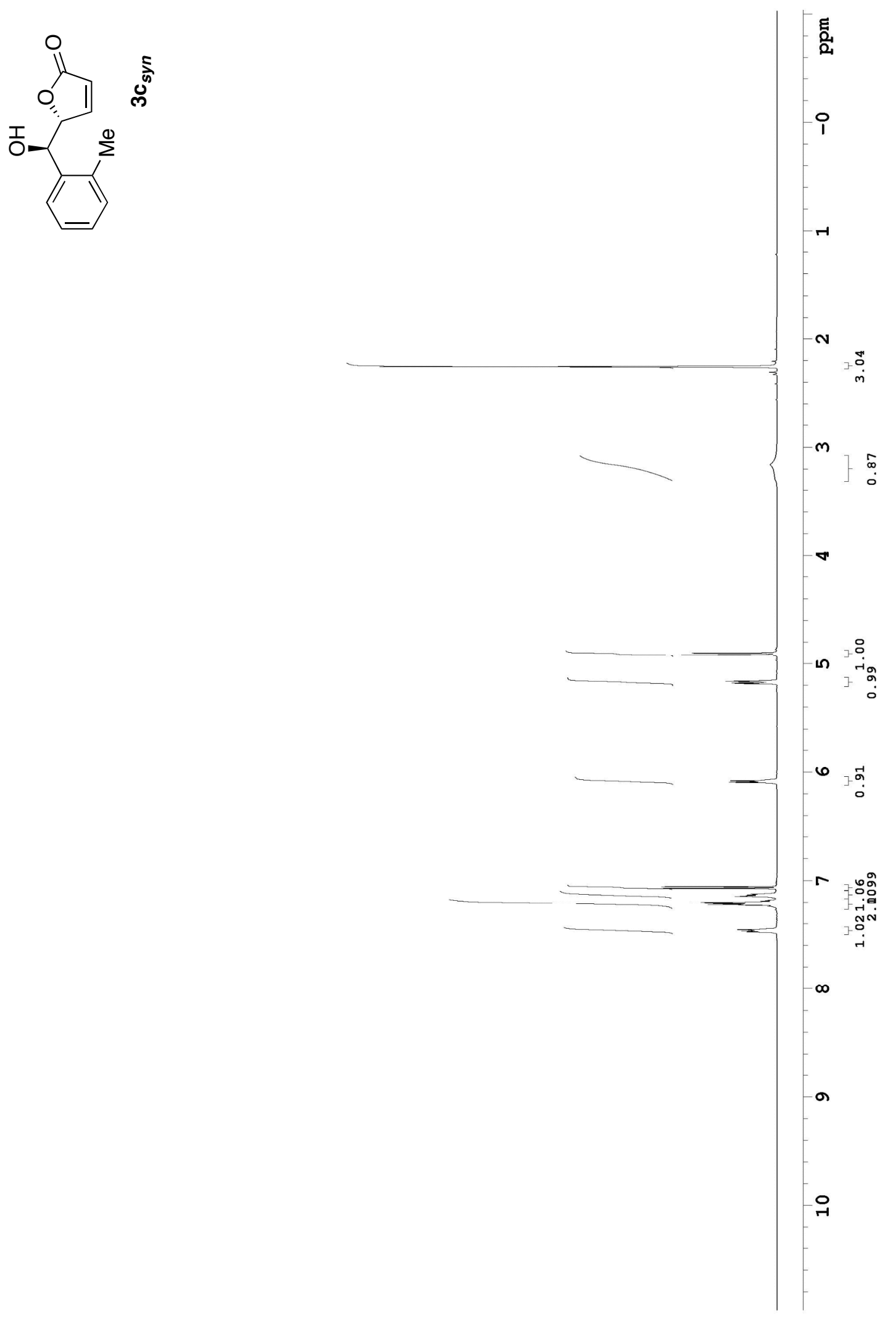

S-13 

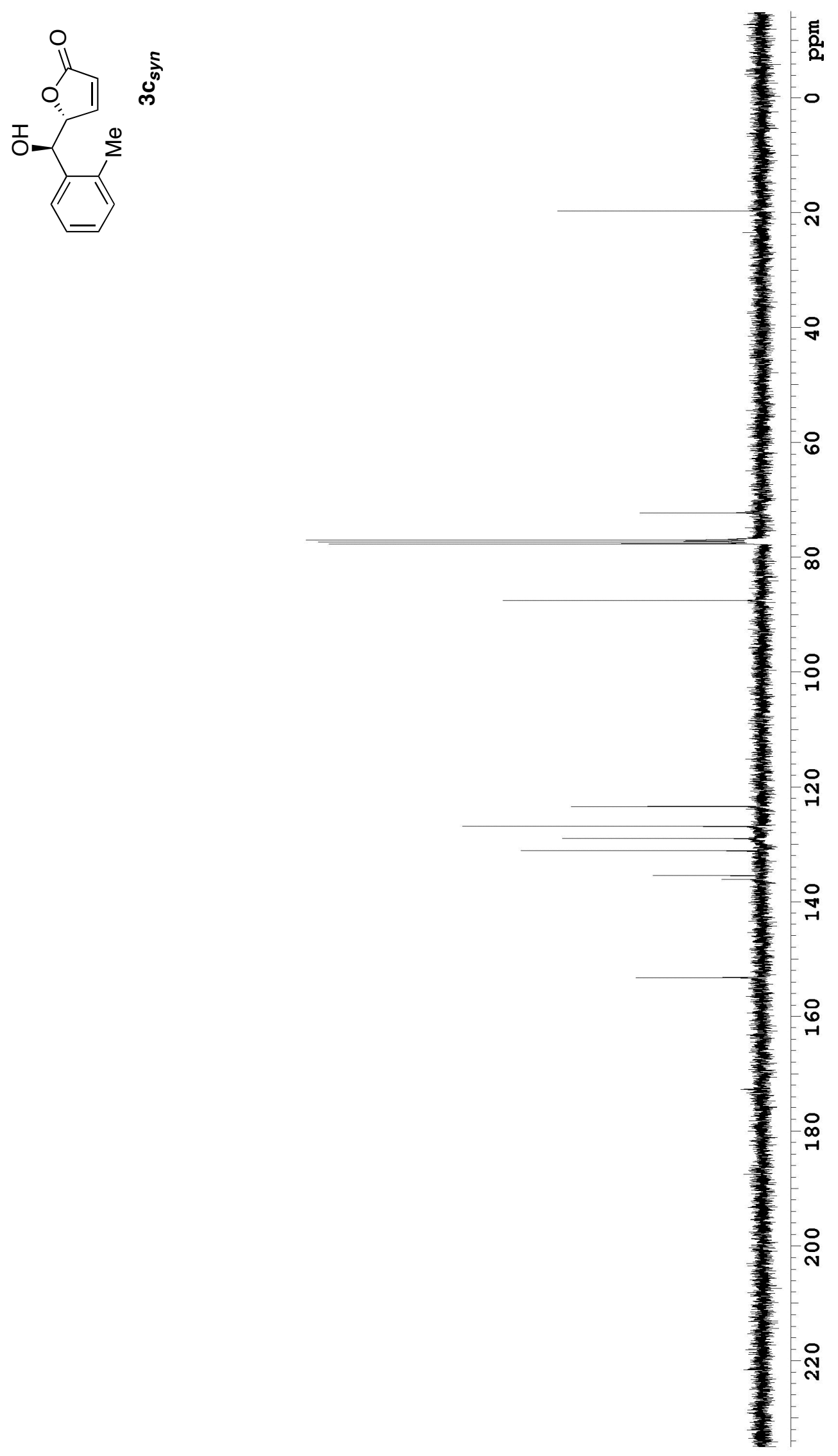


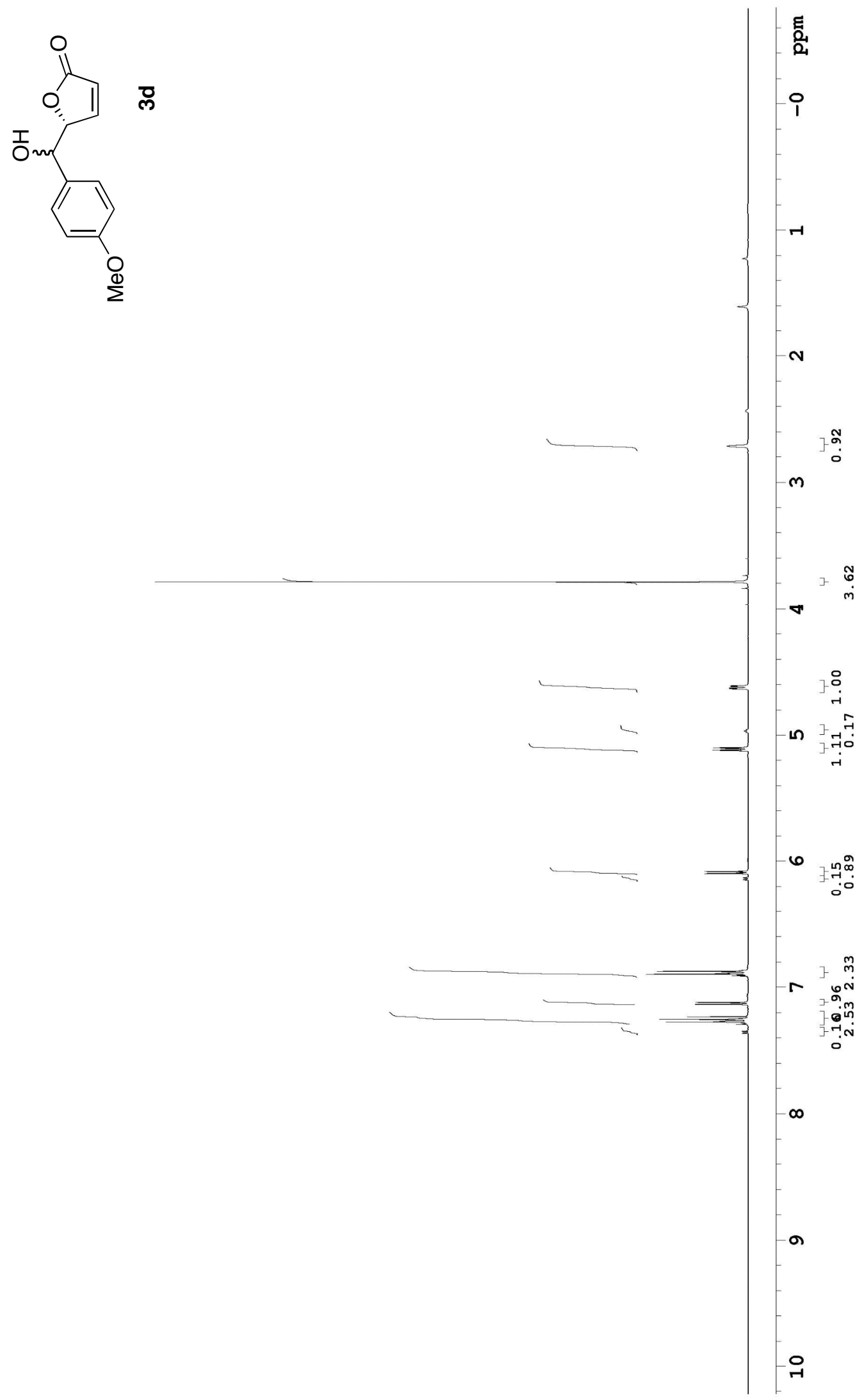

S-15 

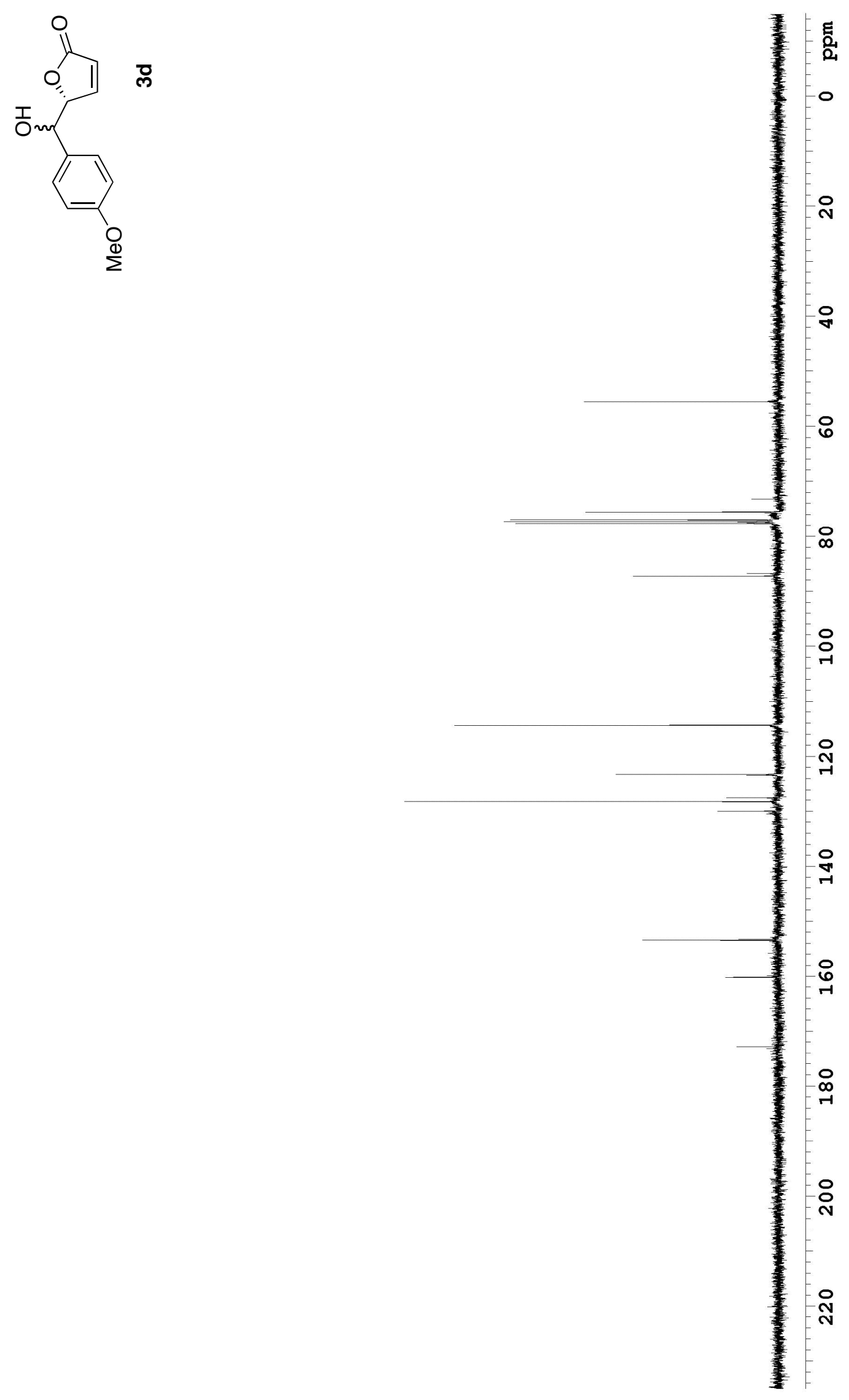

S-16 

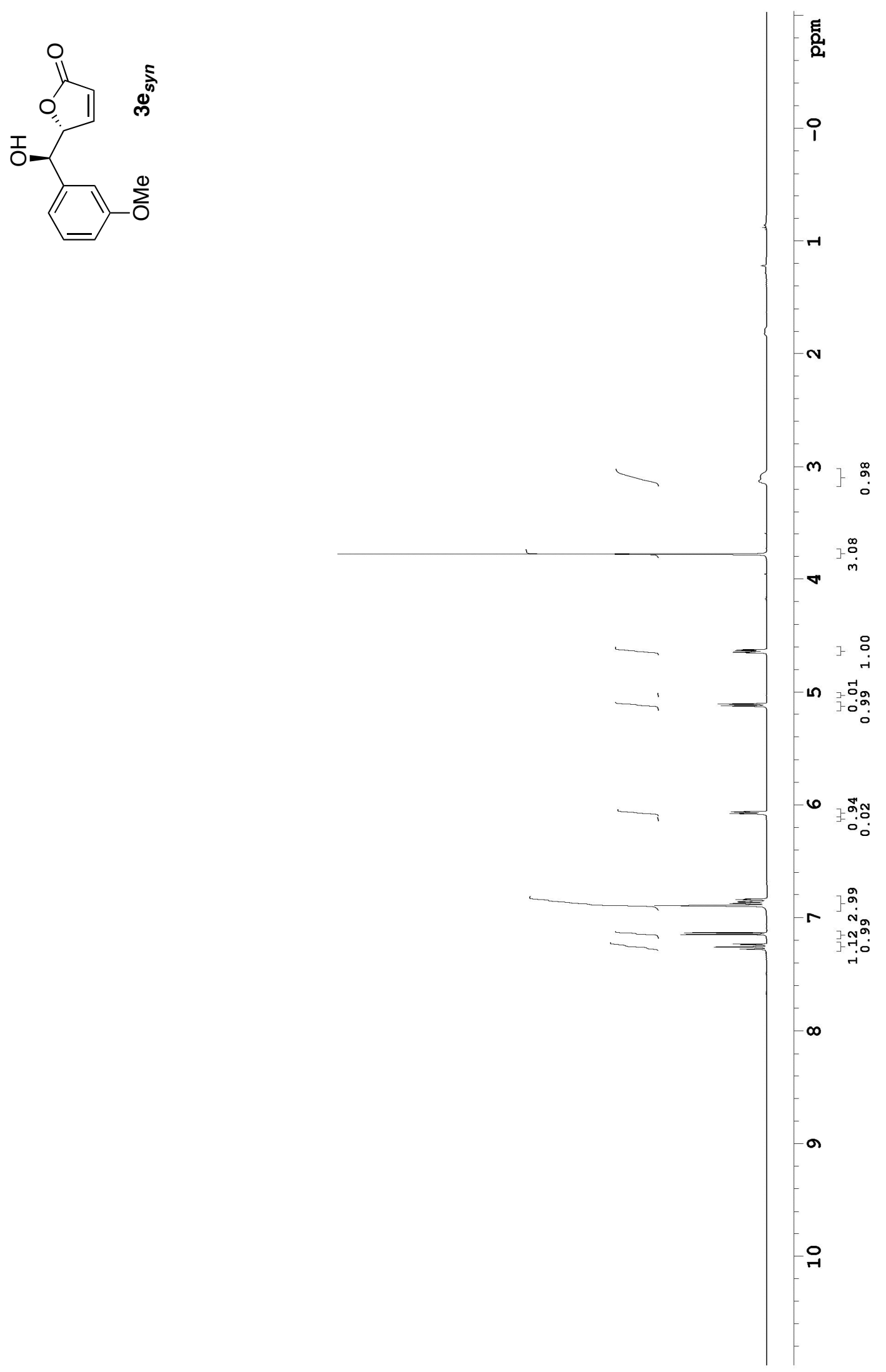


$$
4
$$




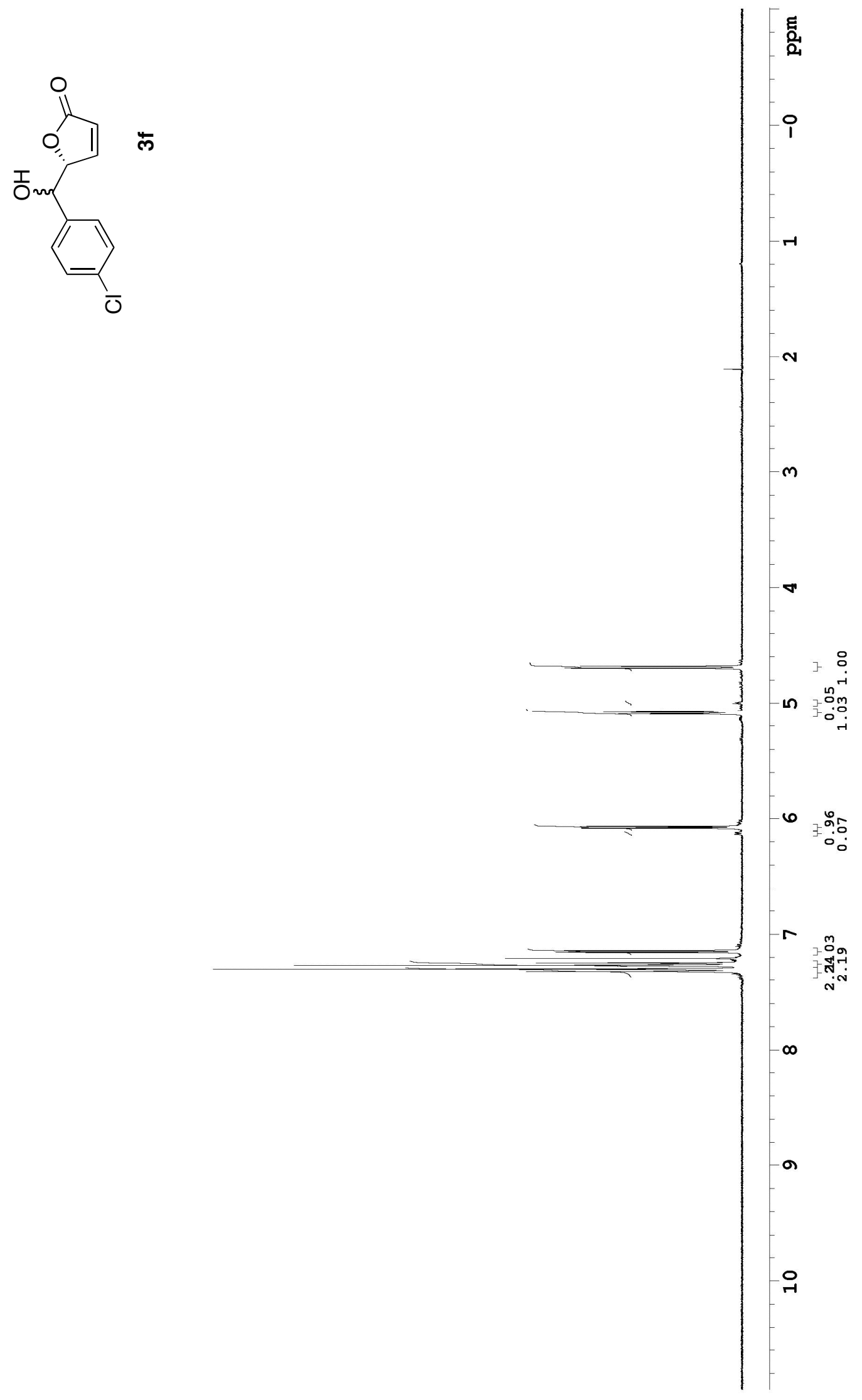




$$
1
$$



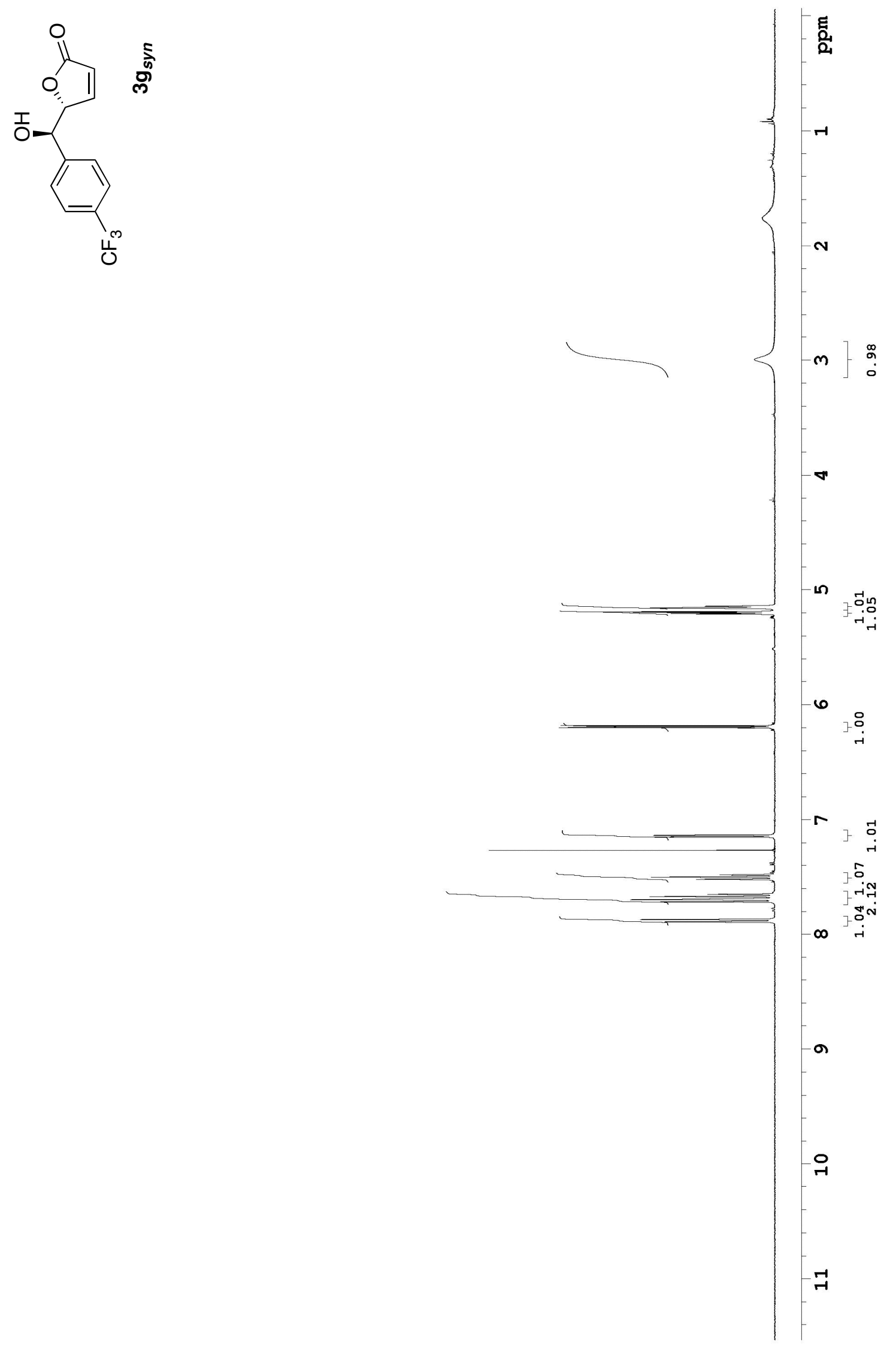


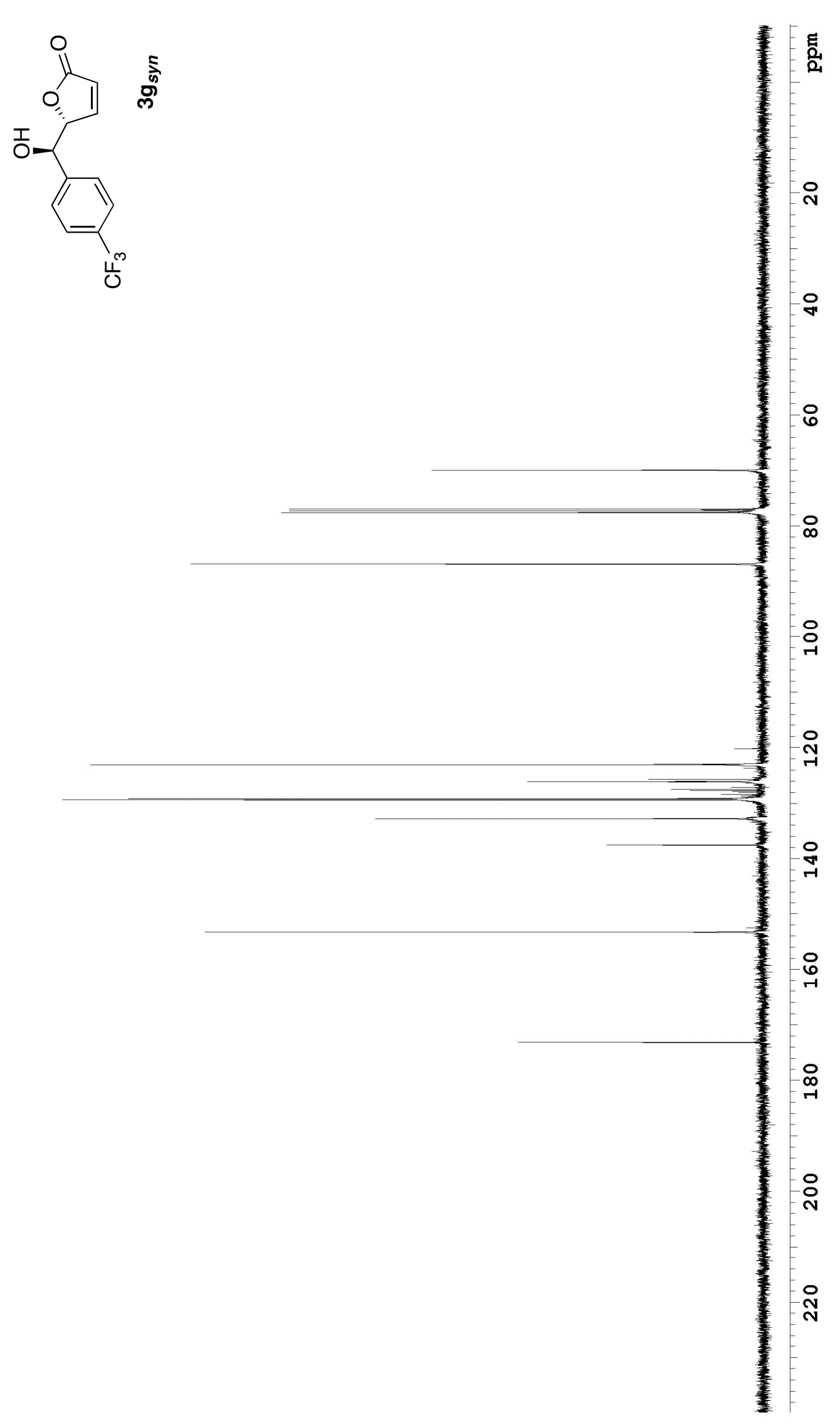



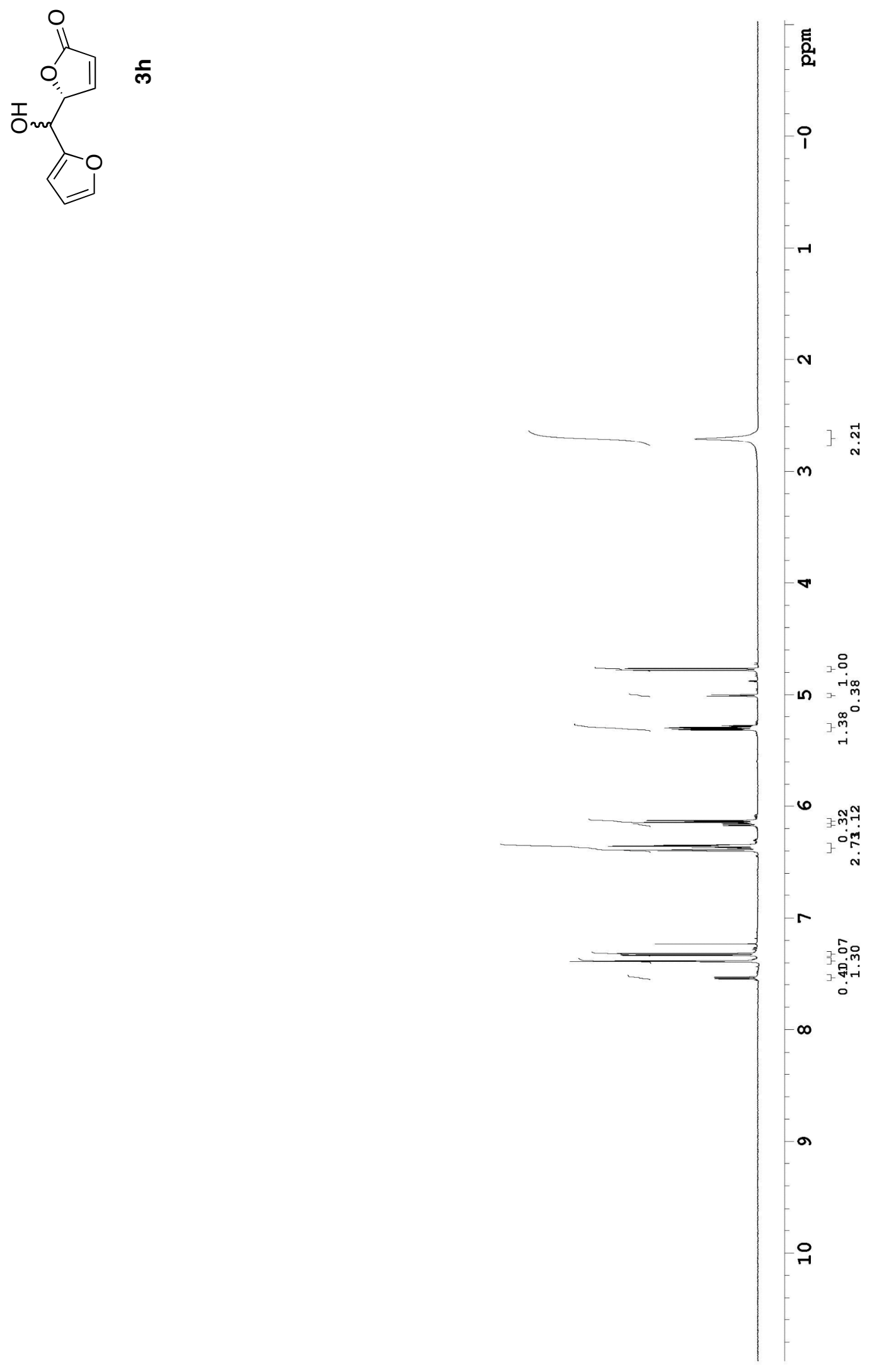

S-23 


$$
1
$$



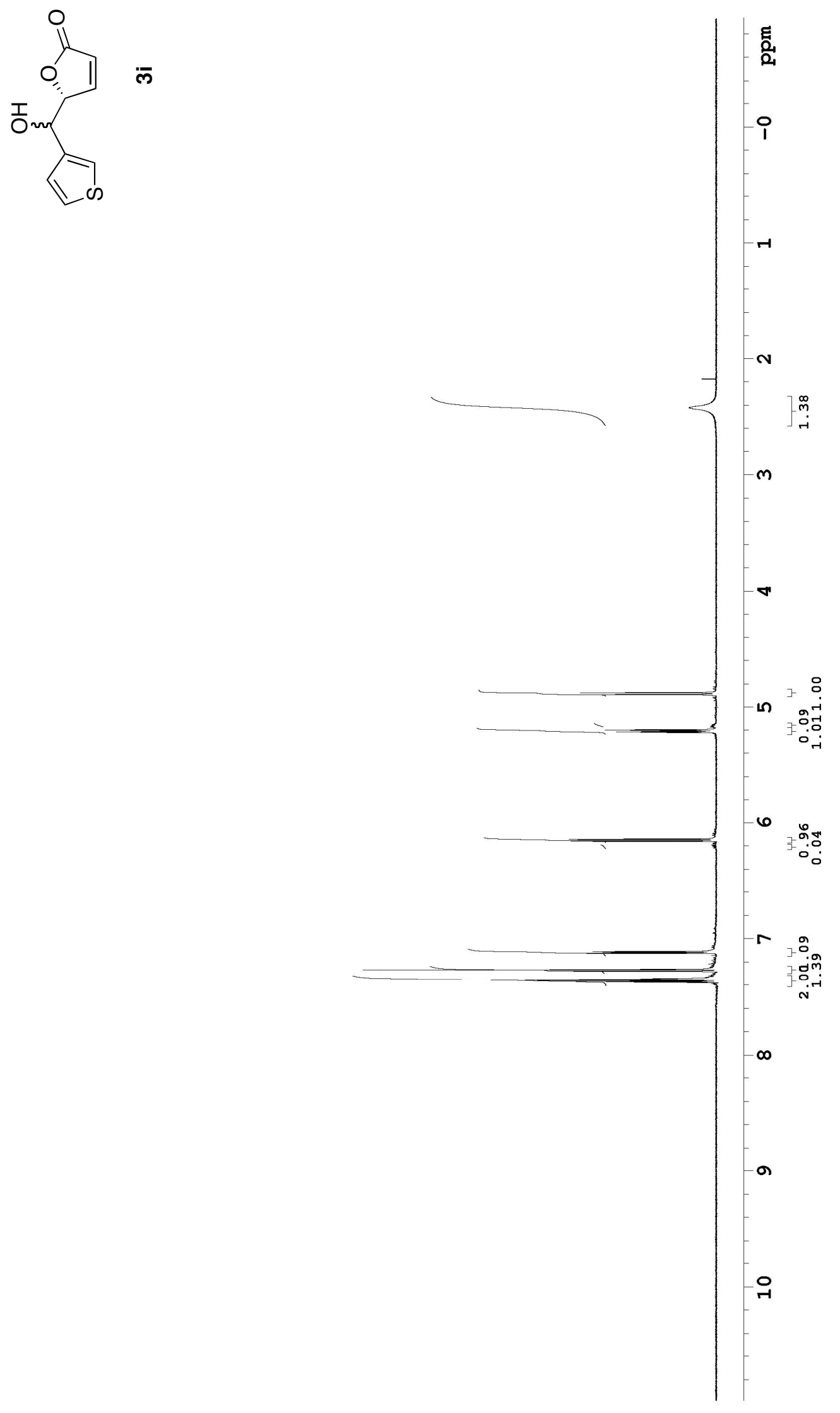

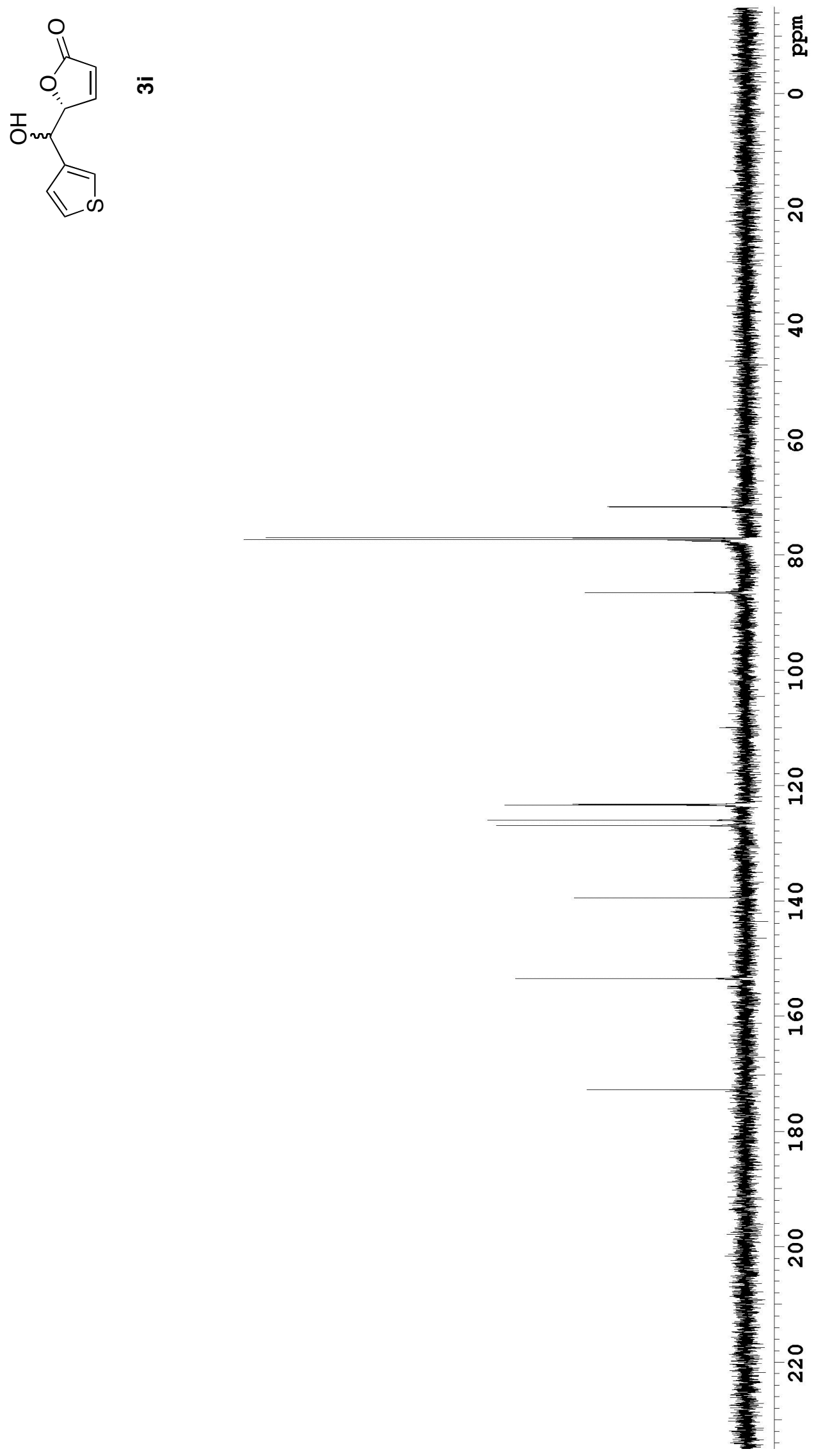

S-26 

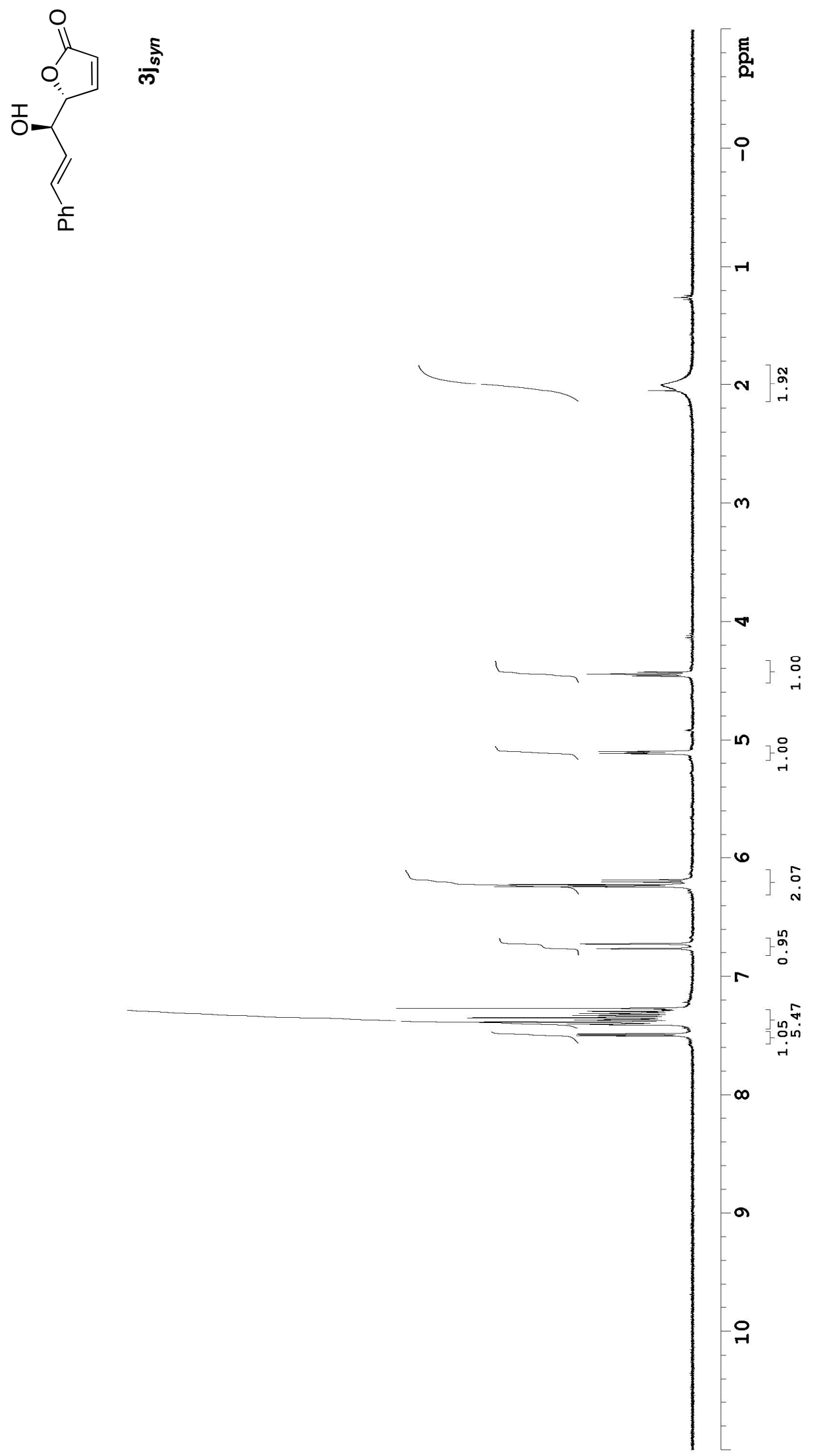


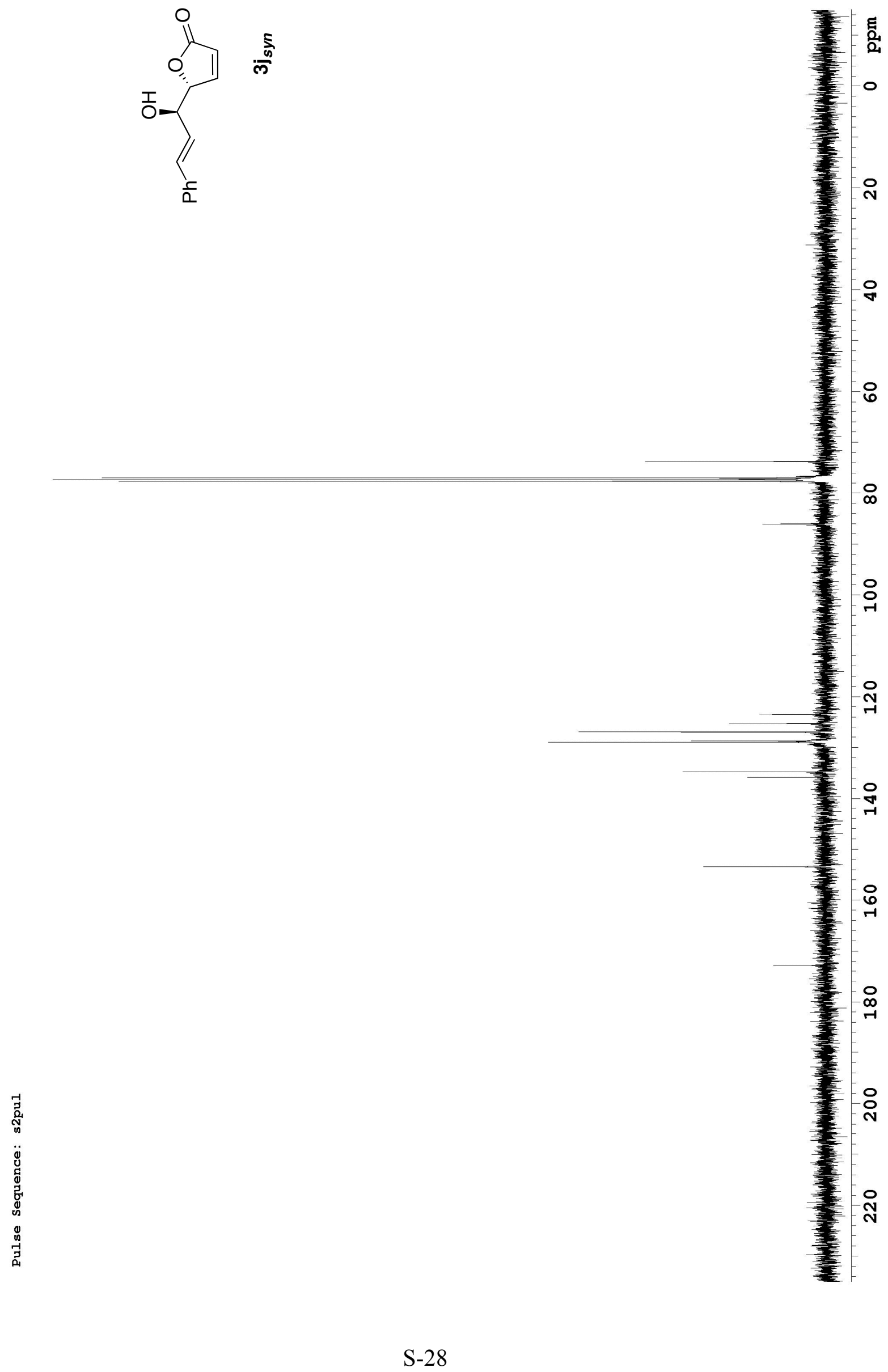



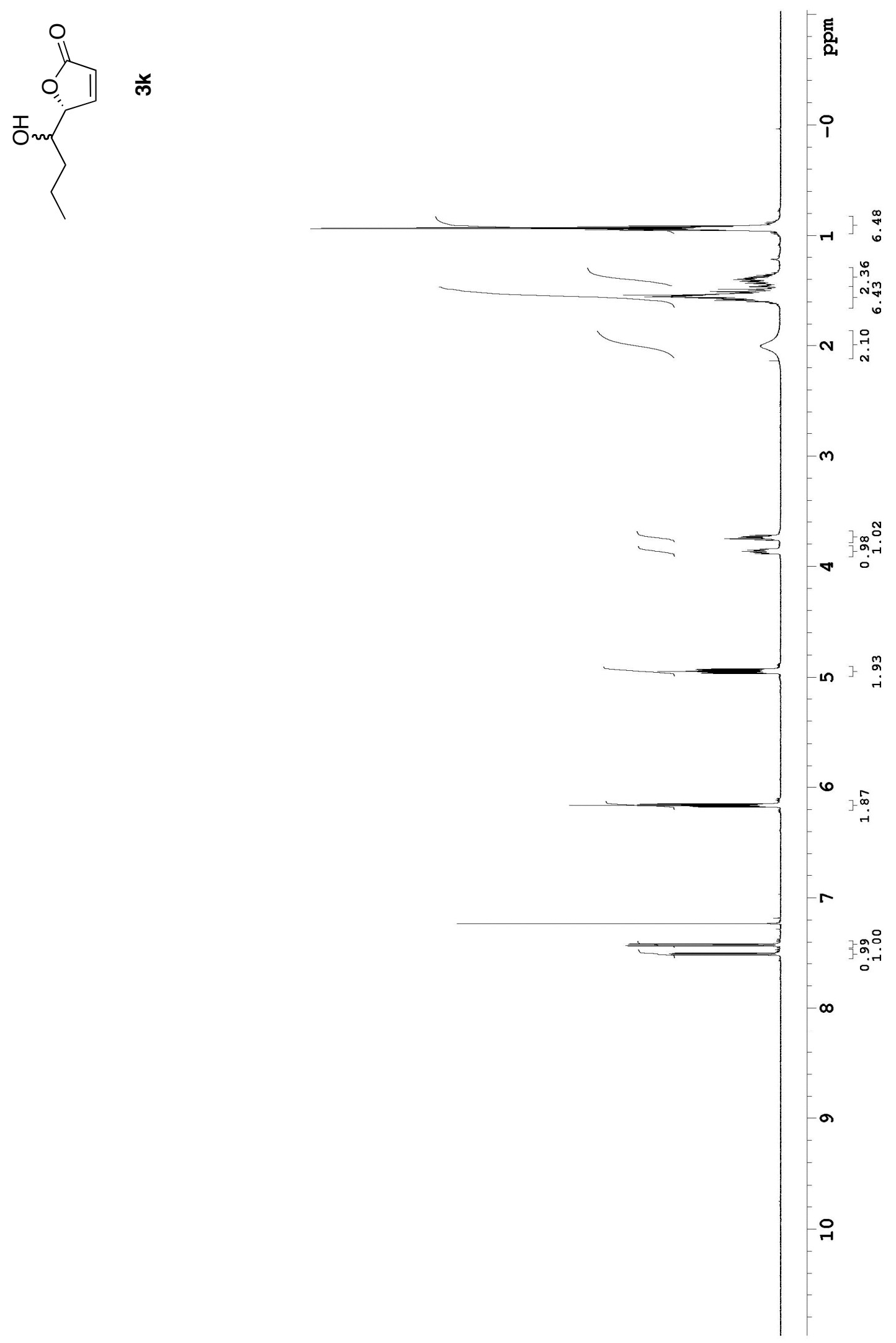


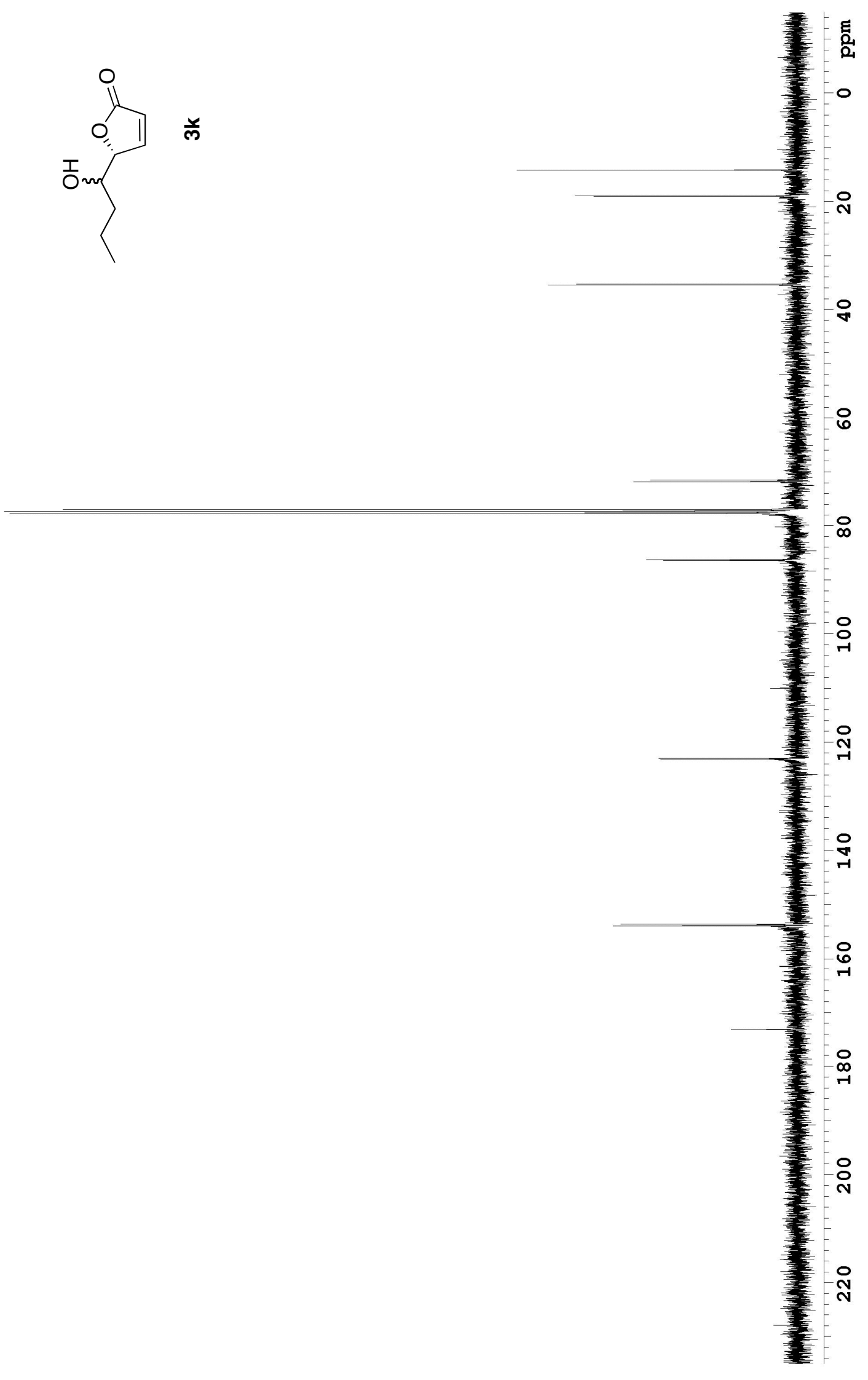

S-30 


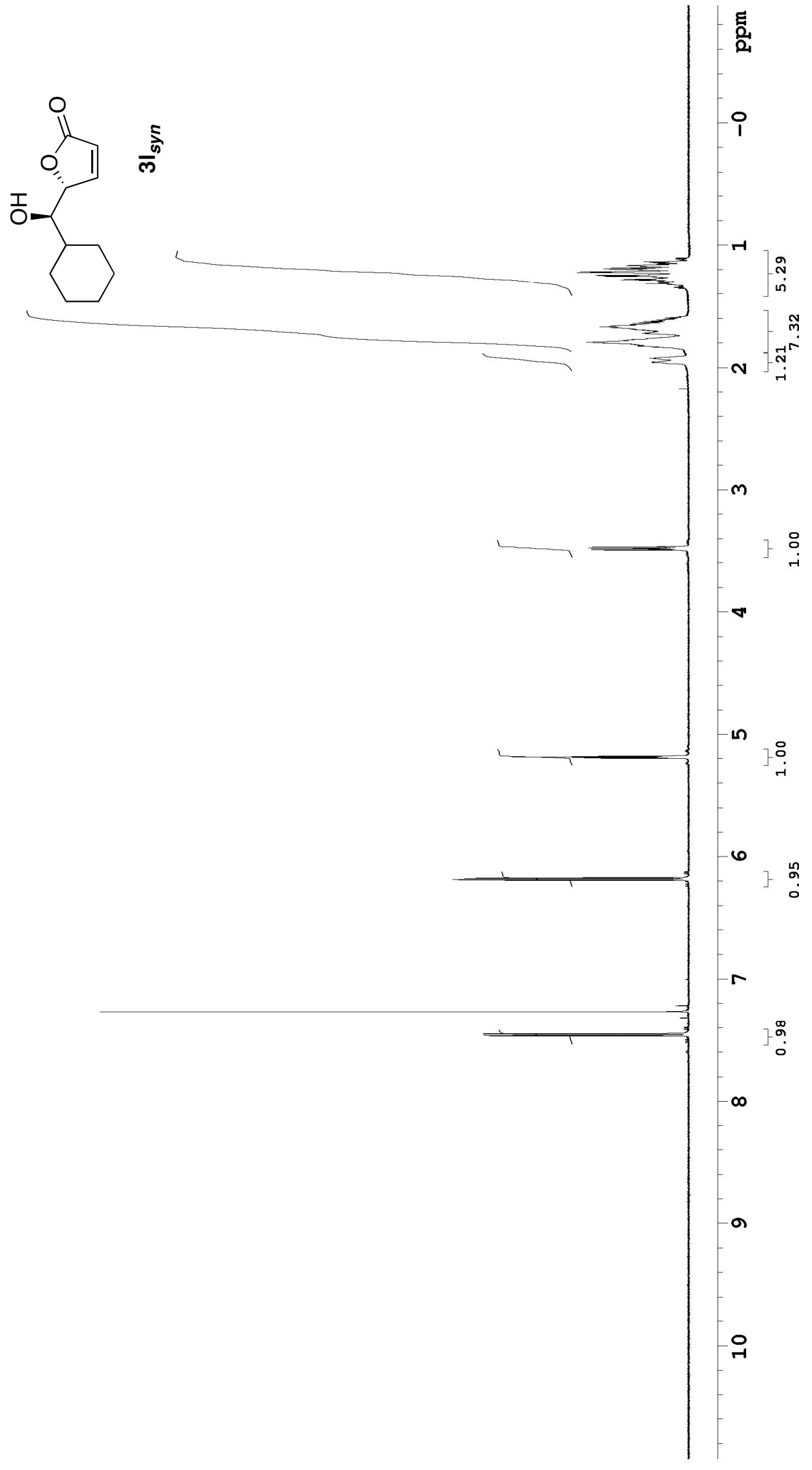



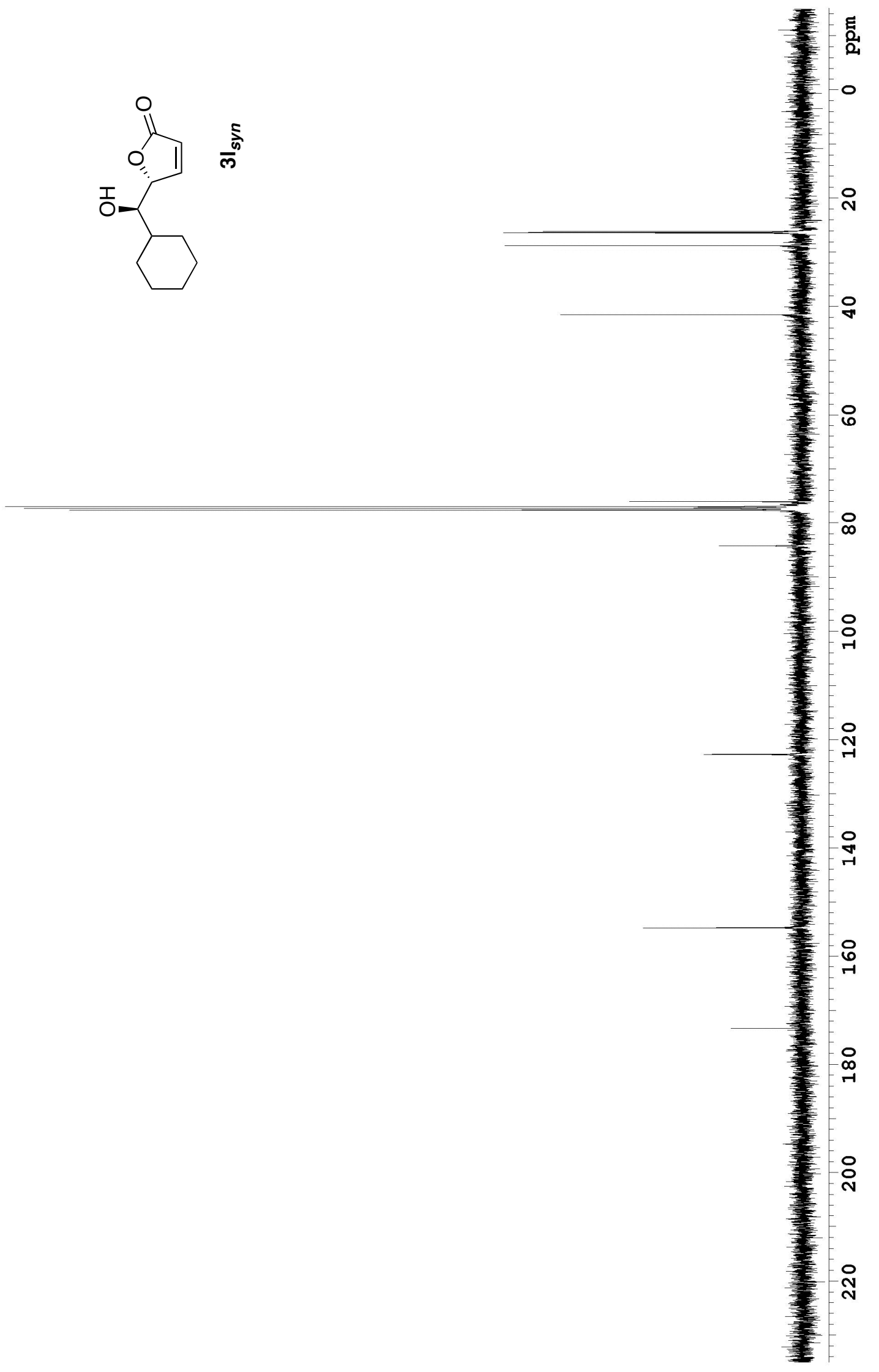

S-32 

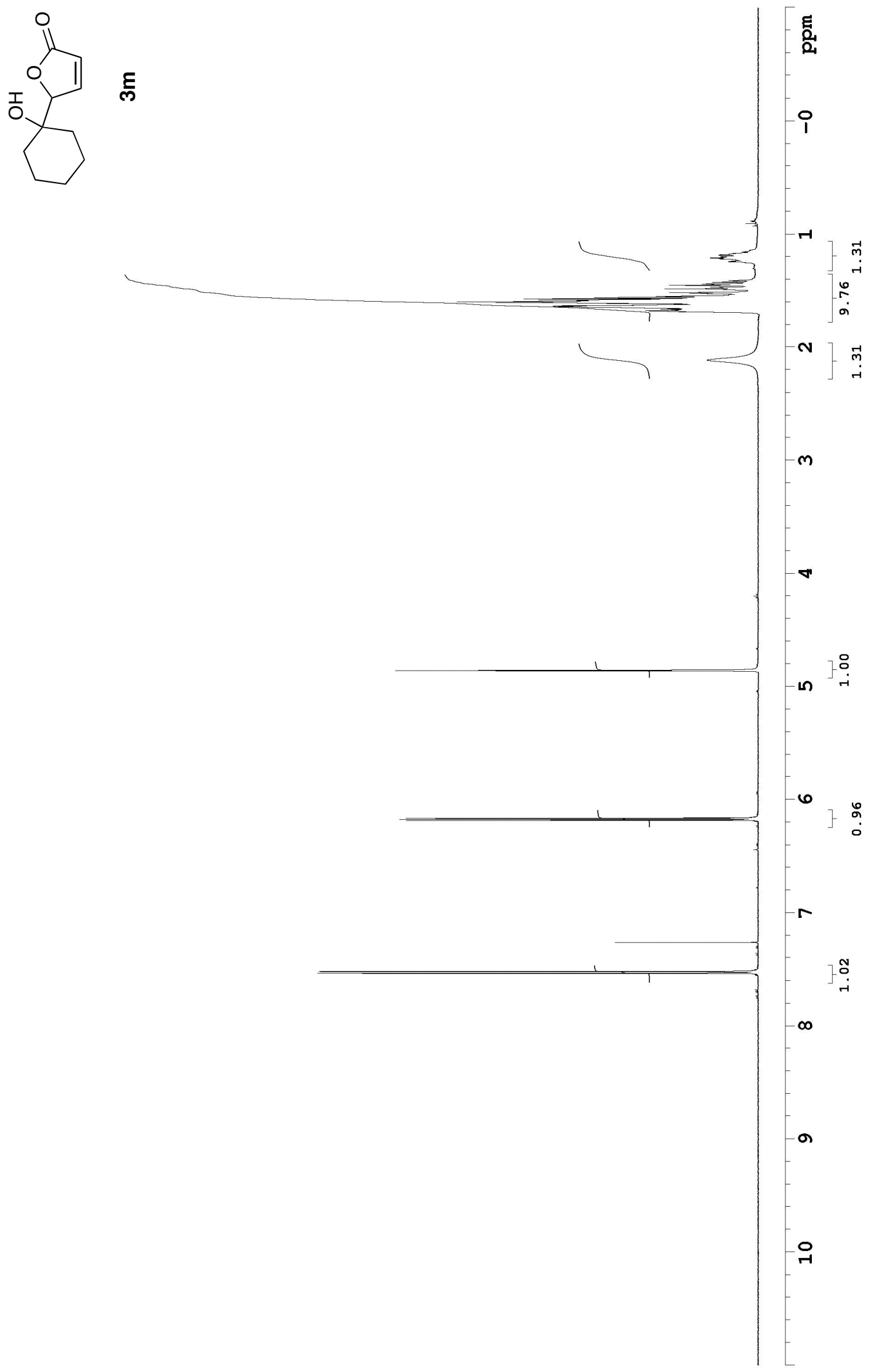


$$
4
$$



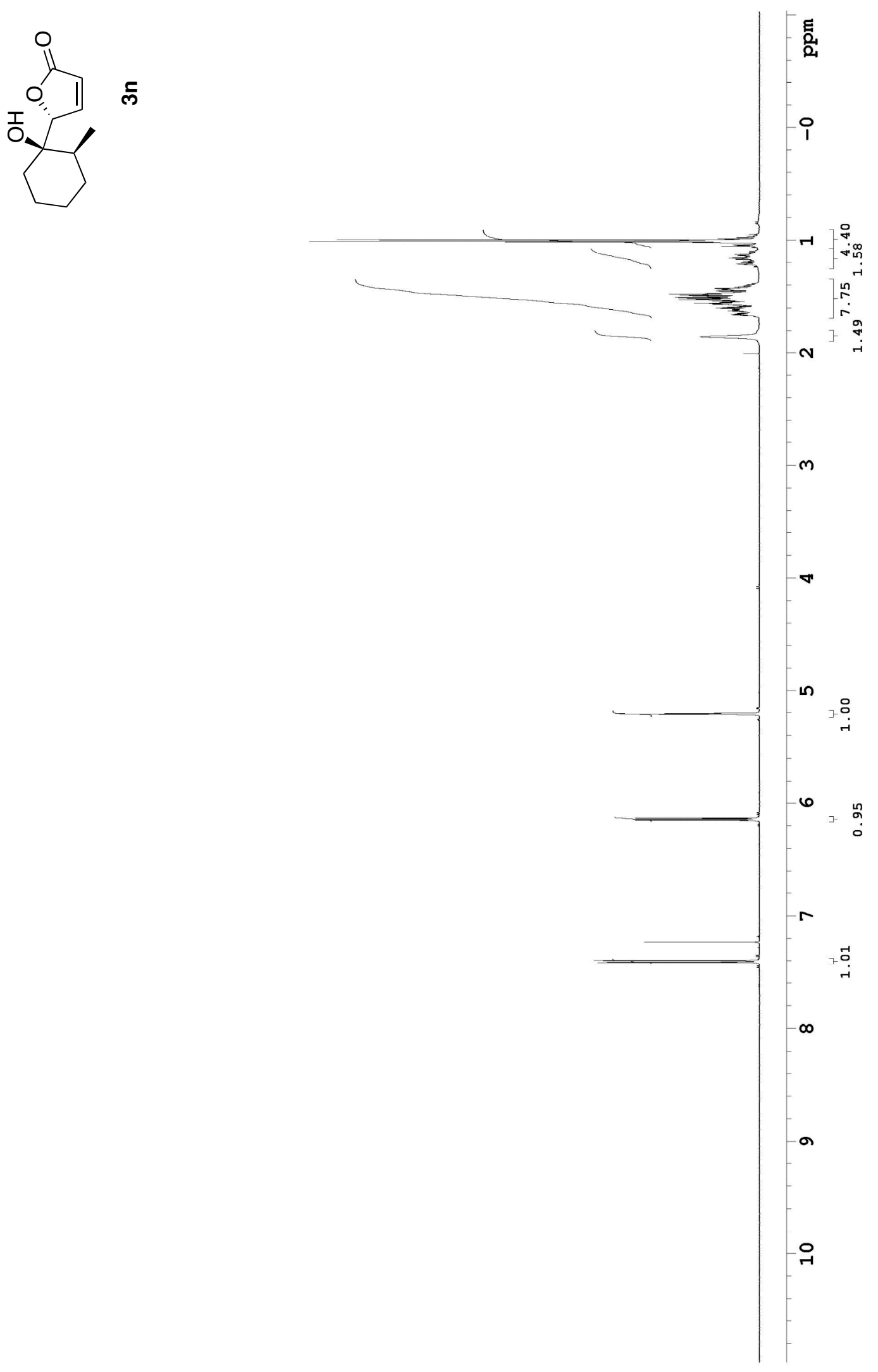

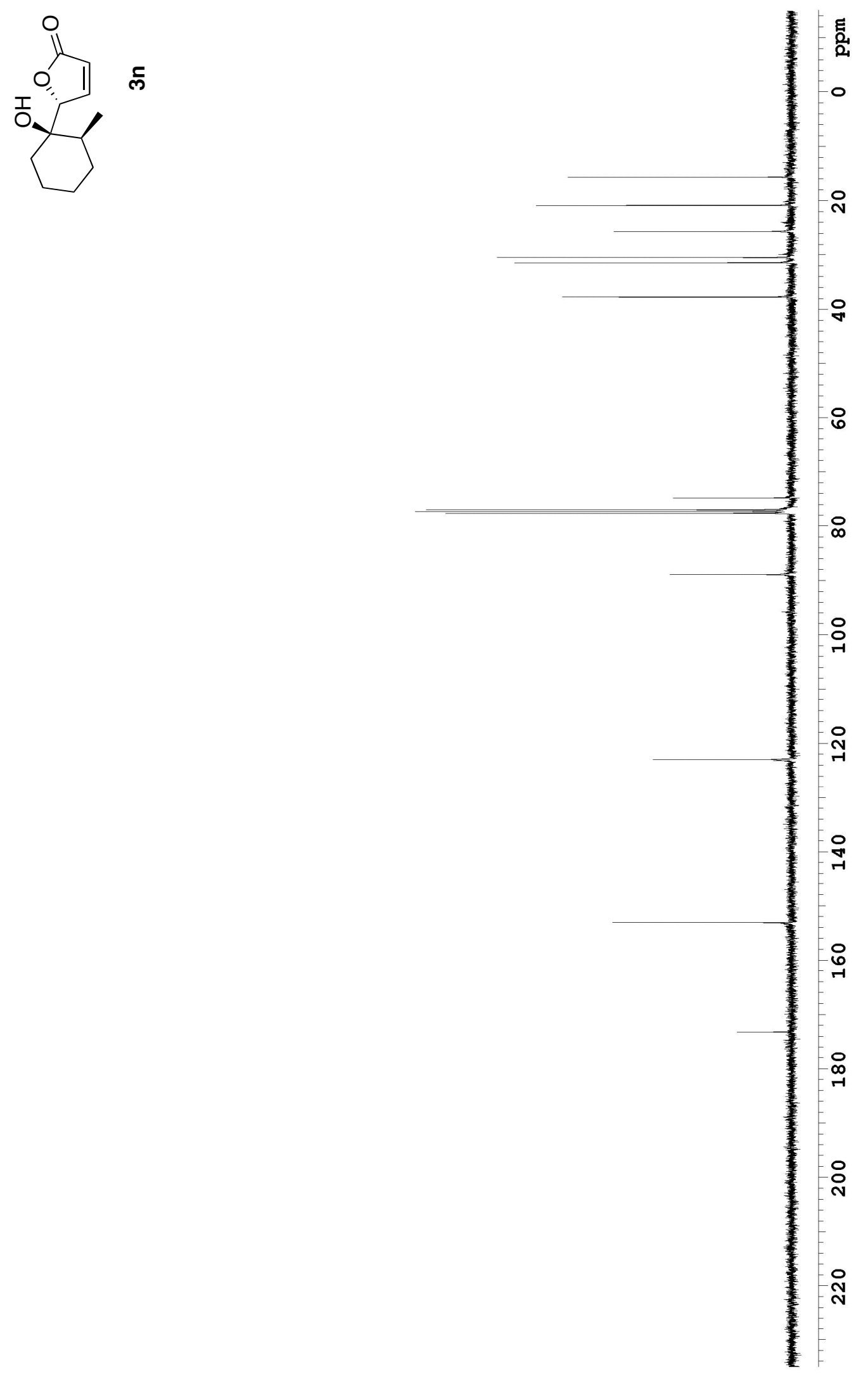

S-36 


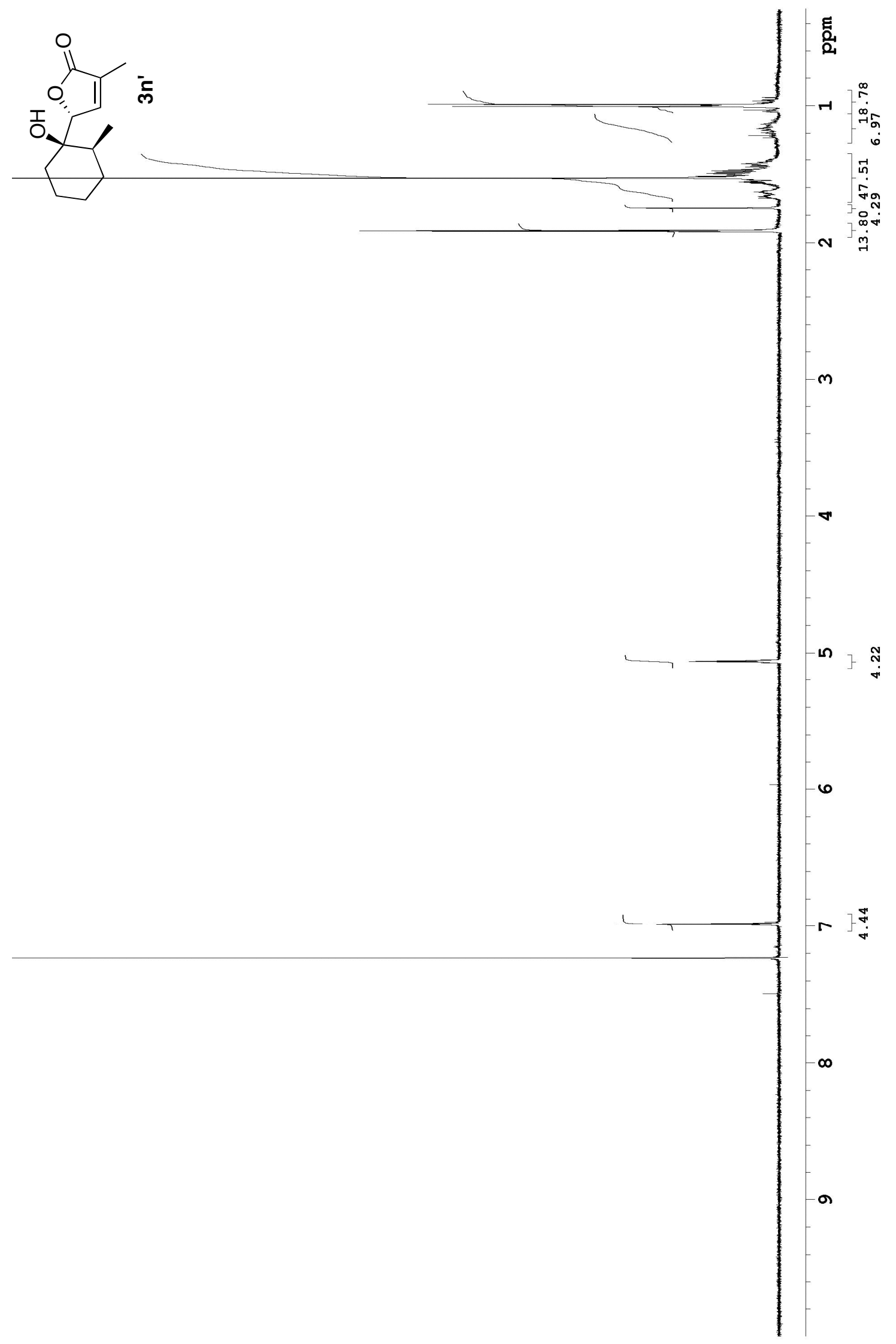




$$
4
$$

